\title{
Linking Europe: The Role of the Swiss Electricity Transmission Grid until 2050
}

\author{
Ingmar Schlecht and Hannes Weigta
}

JEL-Classification: L94

Keywords: Switzerland, energy transition, network extension, investment delay

\section{Introduction}

Electricity markets are currently in a phase of change. In many industrialized countries the markets have been liberalized and renewable energies are becoming an integral part of the production portfolio. Europe is at the forefront in this development with ambitious targets regarding reduction of greenhouse gas emissions, energy efficiency, and integration of renewable energy sources (RES). The long-term objective is a complete transition of the system from national fossil-based markets towards a low-carbon, integrated European market, primarily based on renewable generation (EuropeAn COMMISSION, 2011).

Within this development the transmission system will play a central role as it is required to link the different national markets and transport the increasing amounts of renewable electricity to the demand centers. Given that the existing transmission systems were designed for regulated and monopolized national electricity systems based on centralized fossil generation, the transition will require significant investments in the electric grid, to renew the increasingly antiquated infrastructure and to adapt to the new requirements regarding transmission capacities between and within national markets. The 2014 Ten-Year Network Development Plan (TYNDP) of the European Network of Transmission System Operators for Electricity (ENTSO-E) envisions an investment volume of $150 \mathrm{bn}$ EUR to integrate up to $60 \%$ of renewable energy by 2030 (ENTSO-E, 2014).

a University of Basel, Faculty of Business and Economics, Peter Merian-Weg 6, CH-4002 Basel, Switzerland. Email: ingmar.schlecht@unibas.ch, hannes.weigt@unibas.ch. We would like to thank Sofia Lemhagen, Moritz Schillinger, Nicolas Weidmann, seminar participants at University of Basel and ETH Zurich and an anonymous referee for helpful comments and suggestions. This research was financially supported by WWZ Forum and is part of the activities of SCCER CREST (Swiss Competence Center for Energy Research), which is financially supported by the Swiss Commission for Technology and Innovation (CTI) under Grant No. KTI.2014.0114. 
Switzerland could have a central role in this development as its hub position between Northern and Southern Europe links the three biggest Central European national markets, the German-Austrian, as well as the French and the Italian market. Consequently, the Swiss transmission network is an important element of the extension plans as it impacts the market conditions in its neighboring systems. The reverse is also true, as Switzerland's own electricity system is largely impacted by European developments due to its transit role. In addition, Switzerland follows an own energy transition strategy. The so-called 'Energy Strategy 2050' (SFOE, 2012b) rules out the construction of new nuclear power plants and envisages the existing ones to be phased out until 2034. The new strategy is based on two main pillars similar to the European energy roadmap (EUROPEAN Commission, 2013): firstly, harvesting energy efficiency potentials and secondly, the exploitation of domestic renewable potentials, including extensions of existing hydro capacities as well as solar and wind power. Consequently, the extension of the Swiss transmission system will also be a central element of the Swiss energy transition.

The aim of this paper is to evaluate the role of the Swiss electricity transmission system and the planned network extensions in the context of the Central European electricity market development and thereby the Swiss and European energy transitions. While there are several studies that predict market developments under varying conditions only few have a detailed network representation. By utilizing a Swiss market model capturing transmission constraints as well as detailed hydro interdependencies we evaluate the impact of network investments in Switzerland and its neighboring countries on the electricity markets. We base the analysis on the Energy Strategy 2050 scenarios (Prognos AG, 2012), the EU Energy Roadmap to 2050 (European Commission, 2013), and the planned Swiss and European network extensions of the TYNDP and conduct a sensitivity analysis of delayed grid investments. Albeit focusing on numerical simulations the analysis will also provide insights into the socio-economic discussion on social acceptance of investments related to the energy system. By deriving a quantification of potential costs and system stability impacts due to delayed network investments, we can identify whether the currently observed lag in many energy investments poses a threat to achieving the envisioned energy transitions.

The remainder of this paper is structured as follows. Section 2 provides an overview on the role of the transmission system in the Swiss Energy Strategy 2050 and the European electricity market. In Section 3, the underlying market model Swissmod and the utilized data and scenario specifications are presented. In Section 4, the numerical results are presented and discussed. Section 5 summarizes and concludes. 


\section{The Role of the Swiss Transmission System}

As indicated in the introduction, the Swiss transmission system will play a double role within the next decades. On the one hand it will be a central element within the envisioned integrated European electricity system basically linking the Central European markets. On the other hand it has to support the Swiss energy transition by accommodating increasing new renewable (i.e. solar, wind, and biomass) and hydro-based electricity production while ensuring system stability when existing nuclear plants are successively shut down after reaching the end of their lifetimes. Following, we will first highlight the role of the Swiss system in a European context and afterwards within the Swiss Energy Strategy 2050. We will close with a short review on existing network assessments of Switzerland.

\subsection{The Swiss Electricity System as Central Hub in Europe}

Within the European electricity market Switzerland has a central hub position linking the Northern markets with import-dependent Italy. This translates into a relatively even import-export balance that accounts for a significant share of total electricity flows in Switzerland: in 2012 a total of 31 TWh have been imported and $32 \mathrm{TWh}$ exported, while domestic production totals $68 \mathrm{TWh}$. Due to the hydro-dominated nature of the Swiss electricity system, the summer production peak results in high exports during summer and approximately equal high imports during winter.

This also translates into respective network bottlenecks. The upper panel of Figure 1 depicts the number of $\mathrm{n}-1$ violations in the year 2012 for the different lines in the Swiss transmission grid. ${ }^{1}$ Particularly, network areas with large hydro capacities in Southern Switzerland are subject to $\mathrm{n}-1$ violations as the existing $220 \mathrm{kV}$ lines are insufficient to provide the needed transport capacity for the large amounts of electricity. This is also highlighted in the lower panel of Figure 1 which shows the development of $n-1$ cases over the past years. Especially during the summer months the Swiss system is heavily loaded as the snow melt leads to a peak in hydro production. This is also relevant for the future development as the increase in renewable generation capacities, especially photovoltaic panels, can lead to a further increase of grid injections during the summer months.

1 The $\mathrm{n}-1$ security criterion defines a common rule in electricity markets that the system has to accommodate the contingency of one element without violating security limits on the remaining elements. 
Figure 1: Number of $\mathbf{n}-1$ Violations in Switzerland.

n-1 cases 2012
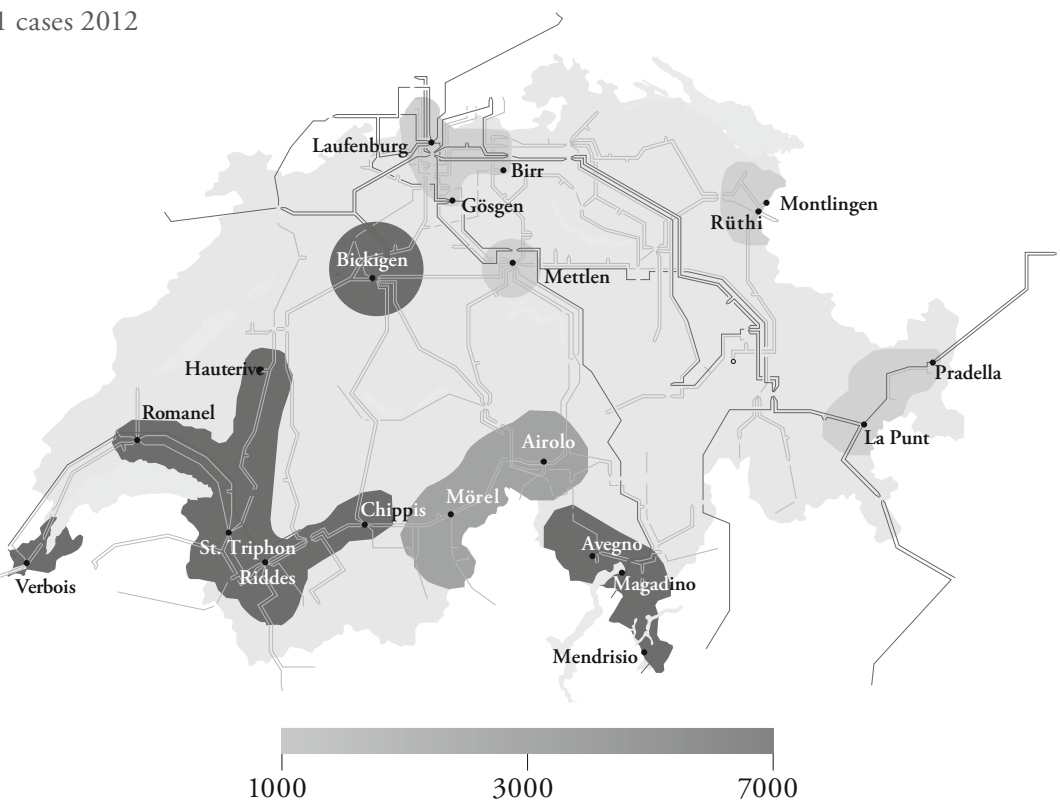

Yearly situation

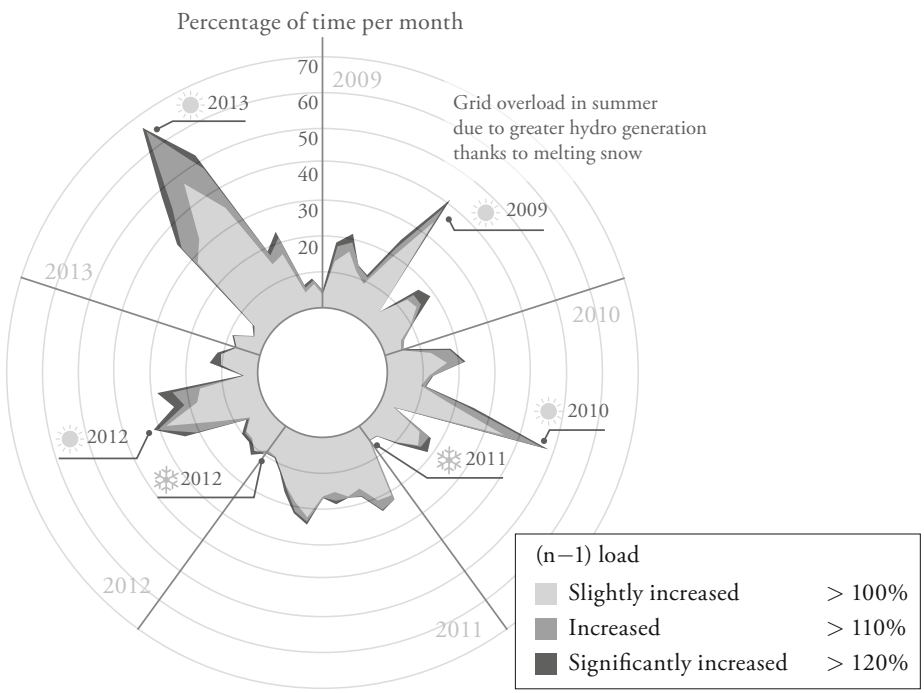

Source: swissgrid.ch 
Given the Swiss electricity system's central role within the European grid, also a large number of extension projects are included in the ENTSO-E TYNDP within Switzerland and its surrounding grids. As indicated by the Swiss Federal Office of Energy (SFOE, 2012a) a large fraction of those investments are based on existing bottlenecks induced by the European market developments as well as modernization and reinforcement investments due to the age structure of the Swiss grid. However, the planned extensions are lagging significantly behind schedule. Of the envisioned 'Strategic Network 2015' (SFOE, 2009) that already included major investments in Southern Switzerland and the North-South corridors only $14 \mathrm{~km}$ have been completed in 2014 with another $17 \mathrm{~km}$ under construction (SWISSGRID, 2014a). Reasons for this delay are, besides necessary new evaluations due to changed regulatory conditions, requirements for potential cable constructions instead of overhead lines and the longsome procedures. This phenomenon is not limited to Swiss transmission investments but a common aspect for many (large scale) energy infrastructure projects within Europe.

\subsection{The Swiss Energy Strategy 2050 and the Transmission System}

The envisioned targets of the Energy Strategy 2050 on the one hand include that the supply of electricity is to be shifted towards (intermittent) renewable generation while on the other hand the demand side is supposed to become more efficient and flexible. Those two sides are linked by the transmission and distribution grids, which consequently take up an important role in the overall transition process.

Given the relatively sudden shift in energy policy after the Fukushima accident, a number of studies have been conducted by the Swiss authorities to evaluate the new situation. A short report by the SFOE (2011) provides a first assessment of the required network related issues that need to be addressed within the Energy Strategy 2050. These include the necessary extensions of the transmission grid, capacity shortages in the distribution system, new transport options like DC transmission, and smart grid developments. In subsequent reports those issues have been addressed in more detail. ConsenteC (2012a) presents an estimate of the transmission network development regarding congestion and the resulting extension requirements based on the expected generation scenarios. Since a large share of Switzerland's grid utilization is induced by European transactions, the analysis is based on a European network model. They show that the main drivers for the future development of the Swiss transmission system are the surrounding European market developments whereas the design of Switzerland's own electricity supply structure only has a minor influence on the transmission 
Table 1: Investment Costs for Grid Upgrades (in Million CHF).

\begin{tabular}{lcccc}
\hline & \multicolumn{2}{c}{ Business-as-Usual } & \multicolumn{2}{c}{ New Policy Package } \\
& Until 2035 & Until 2050 & Until 2035 & Until 2050 \\
\hline Transmission Grid (excl. costs for planned extensions till 2020, ca. 2 billion CHF) & \\
Fossil-based generation & $360-540$ & $430-645$ & $185-280$ & $320-480$ \\
RES-based generation & $360-540$ & $475-710$ & $185-280$ & $330-495$ \\
\hline Distribution Grid & & & & \\
Fossil-based generation & 5550 & 8750 & 6200 & 11150 \\
RES-based generation & 6750 & 10100 & 7500 & 12600 \\
\hline
\end{tabular}

Source: SFOE (2012a), RES: Renewable energy sources

system. They conclude that the expected network extensions by the Swiss network operator Swissgrid are well-suited to address upcoming congestion issues.

Consentec (2012b) provides estimates of the requirements in the distribution system due to increased decentralized generation until 2050. The results are transformed into policy recommendations in SFOE (2012a) that include a faster network extension and transformation towards smart grids and a stronger coordination with the rest of Europe. The total investment costs for the Swiss electricity network range from ca. 11bn CHF to 15bn CHF until 2050, depending on the underlying supply and policy conditions (Table 1). While the transmission system only represents about 2.5bn CHF of those numbers, the investments are focused on few large scale projects that have significant market and cost impacts whereas in the distribution system a multitude of small scale projects need to be carried out.

Given those challenges, the SFOE initiated an 'Electricity Grids Strategy' that aims to increase the efficiency and transparency of network upgrades and extensions to ensure sufficient transport capacity for the envisioned energy transition (SFOE, 2013). The main purpose of this strategy is to clarify and determine the structure of the network extension process and ensure the involvement of all affected actors. In addition, the process shall help to speed up the network extension process and reduce social acceptance issues. A core element of the new structure is the development of a scenario framework for the network planning. These scenarios are developed by the SFOE in cooperation with the network companies and aim to capture potential market developments within Switzerland as well as in Europe. They form the basis of the actual network planning 
of Swissgrid that defines the specific grid reinforcement and extension projects, which are then evaluated. In the long run the Electricity Grids Strategy is to be extended across the transmission and distribution system to allow an integrated assessment of the entire Swiss electricity network.

\subsection{Evaluations of the Swiss Electricity System}

Beside the above presented studies, most analyses of the Swiss electricity market neglect network aspects (see e.g. Mathys, Thalmann, and Vielle, 2012, for a review). An exception is SINGH et al. (2014). They develop a GIS-based network representation to provide a basis for long-term capacity planning using a cost minimizing dispatch model with AC power flow representation. Comparing the modeled network bottlenecks with the eight planned extension projects of Swissgrid they find a high agreement identifying seven of the eight projects at least partially. They conduct a first estimation of the impact of increased wind generation capacity in the system (850MW by 2020) concluding that the grid infrastructure in Switzerland is sufficient to accommodate the increased wind generation.

Furthermore, some European evaluations include detailed network representations and consequently also address the Swiss development. However, as their focus is on the overall European development they typically do not provide detailed results for the Swiss market; e.g., Egerer, Lorenz, and Gerbaulet (2013) analyze different policy scenarios up to 2050 with a European network investment model. Their analysis shows similar investment patterns in Switzerland as in the current extension plans (reinforcement at the Southern border and of the North-South corridors). However, the actual extent of necessary extensions strongly depends on the European market development with higher investment needs in scenarios with high renewable shares. Fürsch et al. (2013) conduct a combined generation and network investment analysis for the European electricity market up to 2050 using an iterative approach with a detailed network representation. They compare a cost-optimal integrated investment simulation with the expected ENTSO-E network extension plan to show that the latter requires higher generation investments and leads to higher average electricity generation costs $(+3.5 \%)$.

In this paper, we extend these existing studies on network aspects with a numerical quantification of the Swiss electricity market. We put a particular focus on transmission investments and their impact on both the Swiss market development as well as induced cross-border effects. By quantifying the consequences of a delayed realization of network extensions we also aim to provide 
insights into the ongoing debate about social acceptance of energy investments and regulatory adjustments to project planning procedures like the Swiss 'Electricity Grids Strategy'.

\section{Model and Data}

To derive insights on the impact of network extension on the Swiss energy transition we rely on a numerical model of Switzerland's electricity market named Swissmod including a detailed transmission and hydro power representation. The general model setup is provided in the following section. Afterwards, details on the data assumptions and scenarios are presented.

\subsection{Swissmod}

The simulation is carried out with Swissmod, a numerical representation of the Swiss electricity wholesale market (Schlecht and Weigt, 2014) following standard electricity market dispatch and network models. Swissmod is designed as a linear programming problem minimizing total generation cost under given demand conditions, although, as described below, we switch to elastic demand and welfare maximization and thus to a quadratic program for this scenario analysis. The model is deterministic, assumes a competitive market with perfect foresight, and uses an hourly resolution for a full year. Swissmod covers the whole transmission system of Switzerland (220 and $380 \mathrm{kV})$ as well as its interconnections to neighboring countries. Generation and demand is allocated on a nodal basis to allow an estimation of congestion aspects. Network constraints are explicitly modeled following the DC load flow approach by SCHweppe et al. (1988) and Leuthold, Weigt, and Hirschhausen (2012).

Due to the high dependence of the Swiss electricity market on hydro generation a particular focus of Swissmod is put on the representation of the different hydro plants and their interaction. The model captures all forms of hydroelectricity in Switzerland: run-of-river, storage, and pumped-storage power plants and integrates them within a network representation of the hydraulic system in Switzerland containing all rivers and lakes in the country. Water flows in the system are endogenously determined, so that the outflow of an upstream hydropower plant results in an inflow to a downstream power plant with a defined time lag. Consequently, storage possibilities (upper basin, lower basin) are optimized by the model.

Swissmod is coded in GAMS (General Algebraic Modeling System) and solved using the IBM CPLEX solver. A detailed model description can be found in 
Schlecht and Weigt (2014). For the analysis at hand we adjust the basic model setup by including an elastic linear demand function and consequently switch to welfare maximization instead of cost minimization (see Appendix II). Furthermore, we change the definition of variable costs of conventional power plants in neighboring countries to be increasing in quantity. This is to reflect that our power plant portfolio in those countries is aggregated and actually consist of a number of smaller power plants, each having different efficiencies and therefore different variable costs. Since the most efficient plant of one technology in a perfectly competitive market would always dispatch first, this is equivalent to assuming variable costs which are increasing in quantity. The mathematical model formulation is provided in Appendix I and II.

\subsection{Data}

We rely on the 2012 calibration of Swissmod as a starting point (SCHLECHT and Weigt, 2014). The basic representation of the Swiss transmission grid is taken from SwISSGRID (2012) and adjusted using locational information from the collaborative mapping project OpenStreetMap. Line parameters are standardized for each voltage level and based on Fischer and Kiessling (1989). Crossborder lines are based on the ENTSO-E grid map and ENTSO-E (2013) data. The details of the existing Swiss hydro generation portfolio are taken from SFOE (2012c) and complemented with hydrological information from BAFU (2012). The initial structure of the European generation capacities are obtained from the ELMOD modeling community (see e.g. Egerer et al., 2014; Leuthold, Weigt, and Hirschinausen, 2012) and updated using data from ENTSO-E (2013).

We aggregate individual power plants of the neighboring countries to one single representative power plant per modeled neighboring country sub-region for each technology as in (SChLECHT and Weigt, 2014). However, to account for the differences in efficiency within each aggregated power plant we calibrate a linear efficiency curve within each technology ranging within two standard deviations of the average efficiency.

For the analysis of network extension projects, we use the 2014 Ten Year Network Development Plan (TYNDP) by ENTSO-E (2014) as well as more detailed data on Swiss network extension plans as published by Swissgrid on their website (SwISSGRID, 2014b). Appendix IV lists all network extension plans included in our model and provides a graphical representation of the underlying network. For generation capacities as well as fuel and $\mathrm{CO} 2$ price trends in the EU, we use the EU Energy Roadmap to 2050 by the European Commission (2013), which is based on the PRIMES model (CAPros, 2013). We assume equal fuel prices (following 
the overall EU price structure) in all of Switzerland's neighboring countries. For Switzerland, we use the power plant portfolio from the SFOE's reference study for the Energy Strategy 2050 prepared by Prognos AG (2012). We choose the case "E" (RES+Imports) scenario as it appears to be the most likely scenario, given that Switzerland is unlikely to invest heavily in own fossil-fuelled power plants.

For hourly electricity demand, we use input data from ENTSO-E for the neighboring countries and from Swissgrid for Switzerland and calculate hourly average values of the years 2011-2013. The resulting data is then scaled to the trend annual total demand from the EU Commission's "Energy Trends to 2050" (European Commission, 2013) and the Prognos AG (2012) data respectively.

For solar and wind hourly infeed, we use country-level data from HiRTH (2013), which have been generated from historical weather data. We use the 2009 data for our analysis, as the weather profile of this specific year yields country total in-feeds close to average years and is thus well-suited for the analysis of a reference trend scenario. For the regional distribution of renewables within Switzerland we use regionally differentiated potentials and we assume that renewables capacity is built-up proportionately to the regional shares of the potentials. The wind distribution is based on Hergert (2013), solar energy is based on MeteoTEST (2012), ${ }^{2}$ and for geothermal energy we assume an equal distribution. ${ }^{3}$

\subsection{Scenarios}

To evaluate the role of Switzerland within the European electricity grid as well as the impact of network extensions on the modeled system we simulate a series of scenarios with different spatial and temporal characteristics:

\section{Base Case}

Representing the expected realization of the TYNDP following the above described EU and Swiss trend scenarios. The base case represents our benchmark to which the different delays are evaluated.

2 The Meteotest (2012) study, which was contracted by the Swiss Federal Office for the Environment (FOEN), only contains the aggregate solar and wind potentials for Switzerland. However, Meteotest provided us with a regionally disaggregated version of the solar potentials.

3 Regarding the location of geothermal power plants, the website geothermie.ch provides a map of planned projects. Yet, since it is unclear which projects are actually going to be realized, and the project map includes projects spread over most of Switzerland, we assume an equal distribution among load centers by reducing demand proportionately. http://www.geothermie.ch/ index.php?p=deep_geothermal_projects. 


\section{Swiss Delay}

In relation to the base case all inner-Swiss extension projects excluding cross-border lines are delayed by five years ( $\mathrm{CH} 5 \mathrm{y}$ delay) and ten years $(\mathrm{CH} 10 \mathrm{y}$ delay), respectively.

\section{European Delay}

In relation to the base case all European extensions included in the model and all EU-Swiss cross-border extension projects are delayed by five years (EU 5y delay) and ten years (EU 10y delay), respectively.

\section{Full Delay}

In relation to the base case all extension projects are delayed by five years (All $5 \mathrm{y}$ delay) and ten years (All 10y delay), respectively.

\subsection{Model Assumptions and Limitations}

The presented numerical framework requires simplifying assumptions and restrictions to keep the model solvable which in turn impact the obtainable results. The Swissmod framework is deterministic in nature and assumes a perfect competitive market environment. In consequence, the obtained market prices will represent a lower boundary on real world market outcomes as stochastic influences and strategic company behavior are omitted. Similarly, the parametrization is based on average historic demand levels and representative renewable injection values which add to the underestimation of extreme events.

The geographic limitation to central Europe and the neglect of imports and exports beyond that geographic scope is likely leading to overestimation of price fluctuations within the simulated countries. To the contrary, the aggregated representation of Switzerland's neighboring countries and omitting unit commitment aspects is likely to underestimate price volatility during times with rapid demand changes.

As the model does not include an investment framework, the generation, transmission and demand structure is externally defined. Therefore, the obtained market prices do not necessarily suffice to refinance those capacities. Furthermore, the dynamic interactions between those three market segments are not captured; i.e. in case of delays in network extension it is likely to assume that the projected power plant investments will be impacted.

Finally, the Swissmod framework is based on a nodal representation of the Swiss transmission system whereas under current market conditions network aspects are neglected on the wholesale level and managed via re-dispatch. The simulated market results represent the optimal plant dispatch given network 
restrictions and can be interpreted as equivalent to a post-re-dispatch evaluation that translates the necessary re-dispatching costs into locational wholesale prices.

In general the simulation results should be suited to represent average market conditions given the underlying price and capacity numbers but will fall short on the impact of short term events and uncertainty.

\section{Scenario Results}

Following, we first present the base case results up to 2050 highlighting the average expected market trends if the network extension occurs as expected in the TYNDP. Second, we summarize the general findings of the different delay scenarios focusing on aggregated results. Finally, we discuss detailed implications of delayed network investments focusing on effects on national rents, the role of European coordination, and the impact on the Swiss electricity market.

\subsection{Base Case Development till 2050}

In view of the model focus on Switzerland and its neighboring countries and the externally defined developments of generation capacities, demand, and prices, the results are mostly driven by the expected European energy trends. ${ }^{4}$ The large increase in available RES capacities by the factor three between 2015 and 2050 also translates into a similar increase in total RES generation till 2050 (Figure 2, upper panel). At the same time conventional power plants greatly reduce their output. Nuclear generation drops to approximately $65 \%$ of the 2015 values by 2050 due to the phase-out in Germany and Switzerland. Coal and lignite-fired plants experience the largest decline to less than $30 \%$ of the 2015 values while in turn gas-fired plants increase their output by $80 \%$. The shift from coal to gas

4 Comparing our model results with the generation figures of the EU energy trends (European Commission, 2013) shows a general divergence in the dispatch of gas plants. In our model Germany has a lower gas output and France and Italy a higher one than in the simulations of the PRIMES model of the EU energy trends. This divergence can be a result of several effects that differentiate the models: first, our model has a more detailed network structure that can lead to different dispatch situations, second, we neglect imports and exports beyond the covered countries, third, we use an aggregated linear cost structure for fossil generation, and fourth, we assume similar fuel prices in each country. Especially the latter two effects can lead to a higher incentive in our model to utilize gas units in each country instead of a potentially more regionally differentiated pattern. 
is driven by the assumed increase in permit prices until 2050 (Figure 2, lower panel). As fuel prices remain rather stable in the European energy trends the high permit price basically renders coal uncompetitive compared to natural gas.

Figure 2: Average Aggregated Dispatch and Electricity Price Developments till 2050.
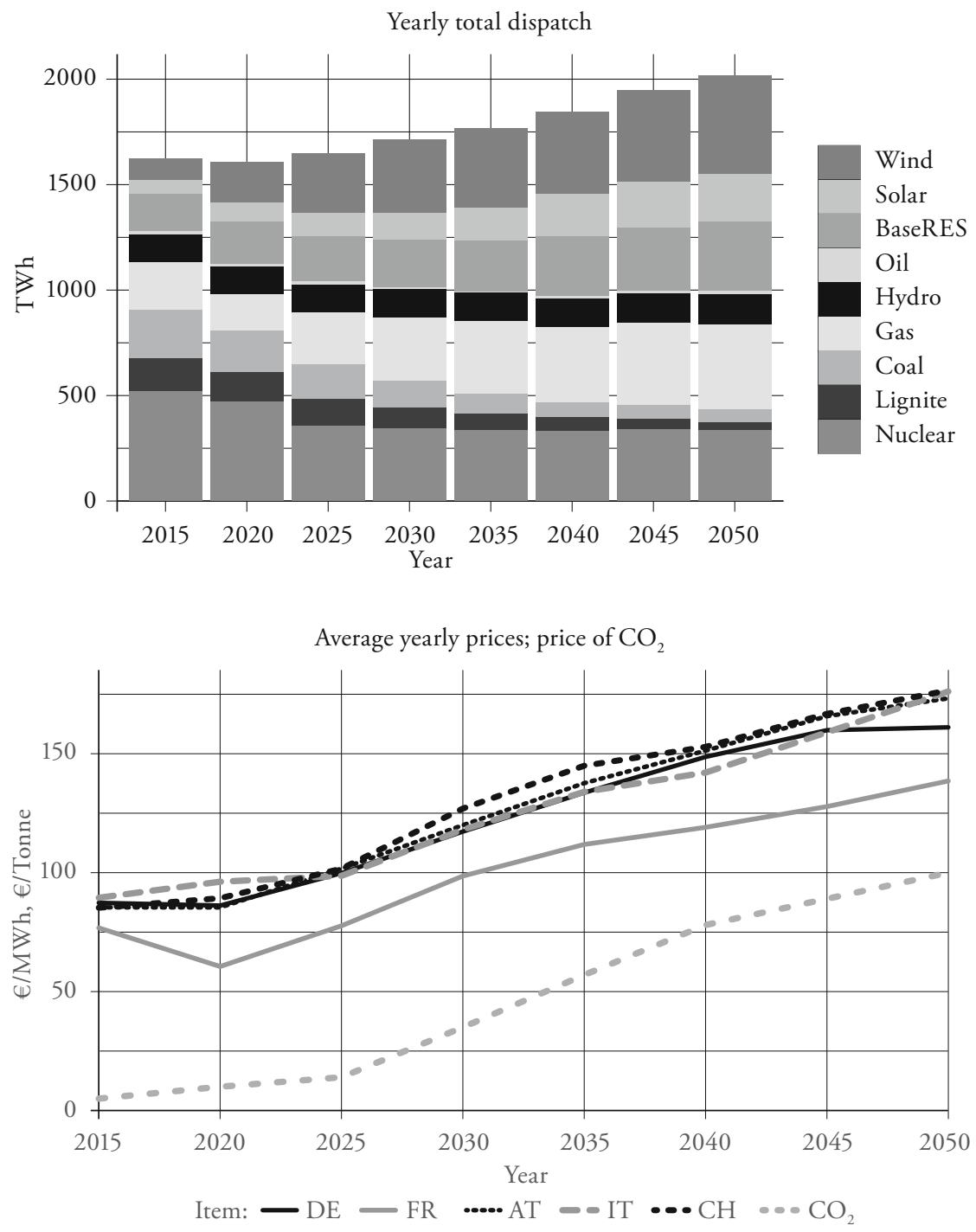

Swiss Journal of Economics and Statistics, 2015, Vol. 151 (2) 
The impact of the expected network extensions is best observed when comparing the different country prices (Figure 2, lower panel). Within the model framework France always faces lower prices than the other countries. This is mainly due to the large low-cost generation capacities of nuclear and hydro power plants and increasing RES capacities, the exclusion of electricity exports to other countries (i.e. Spain, the Benelux, and the UK), and the limits imposed by the transmission system. Consequently, in the modeled short-run dispatch French electricity prices are defined by domestic low variable cost generation when congestion restricts exports, making France a low-priced market within the modeled grid.

The remaining countries show a much closer related price level, still largely defined by fossil generation as the marginal price setter. Up to 2025 a price convergence can be observed while from 2030 onwards the prices slowly diverge again. This mirrors the impact of the expected TYNDP extensions, since prices naturally converge when there is little congestion and diverge as soon as crossborder limits are binding again. On the one hand the planned network extensions address the expected congestion problems of the next decade and if realized, they fulfill their goal and bring prices closer together. On the other hand the market model continues up to 2050 with an altered generation mix while the network remains unchanged from 2030 onwards. As changed market conditions will also impact the network they will require further investments which are not yet addressed in current extension plans.

Examining the cross-border flows the exporter role of France becomes even more obvious. On average, France keeps its export on similar levels throughout the observation period (Figure 3, upper panel). Albeit nuclear generation also declines in France this is compensated by a large increase in RES capacities. This mimics the development Germany experienced after the nuclear moratorium in 2011: the reduced nuclear output has been overcompensated by the increase in solar generation leading to increased exports during the daytime and consequently price distortions in Central European electricity markets. In the long run up to 2050 the current relatively balanced export situation in Germany tends to shift towards a higher import share due to the final nuclear phase-out and the modest RES increase in comparison to other countries. The second big change in the export balance can be observed in Italy. While Italy is still import-dependent on an annual average, the absolute level decreases significantly until 2040 with an increase afterwards. This is also an effect of the increase in RES capacities. With the large share of solar generation capacity being installed, Italy becomes a regular export country during the daytime and requires imports during the nighttime. 
Figure 3: Development of Cross-Border Flows.

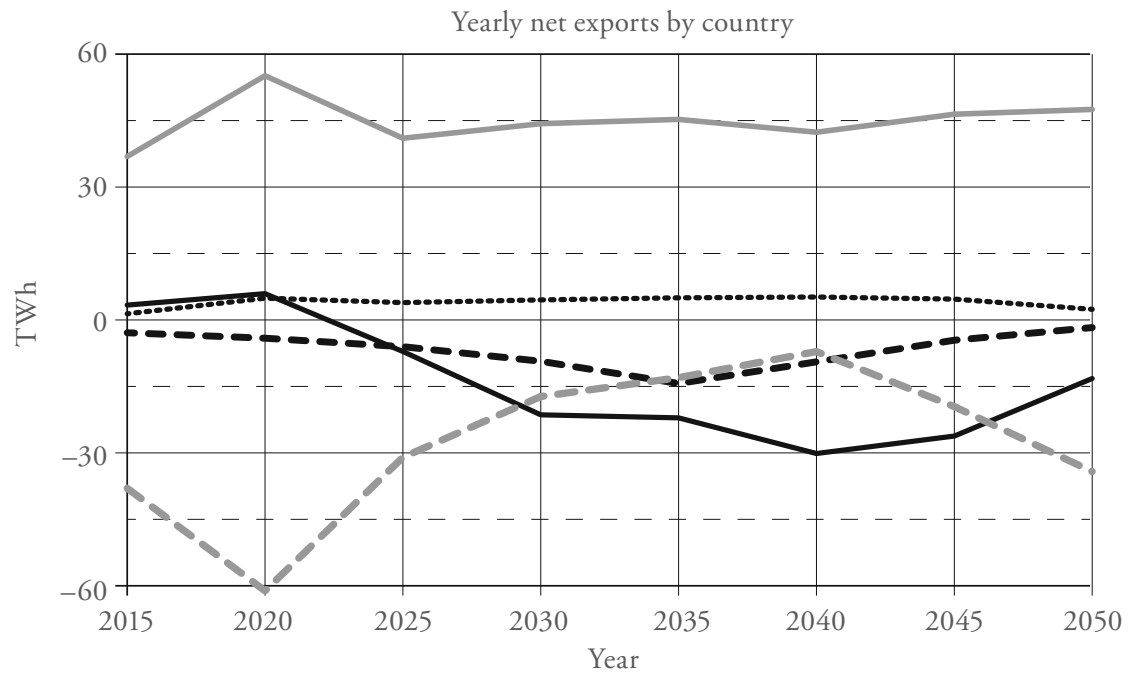

Country: .... AT $\leadsto \mathrm{CH} \longrightarrow \mathrm{DE}-\mathrm{FR}$

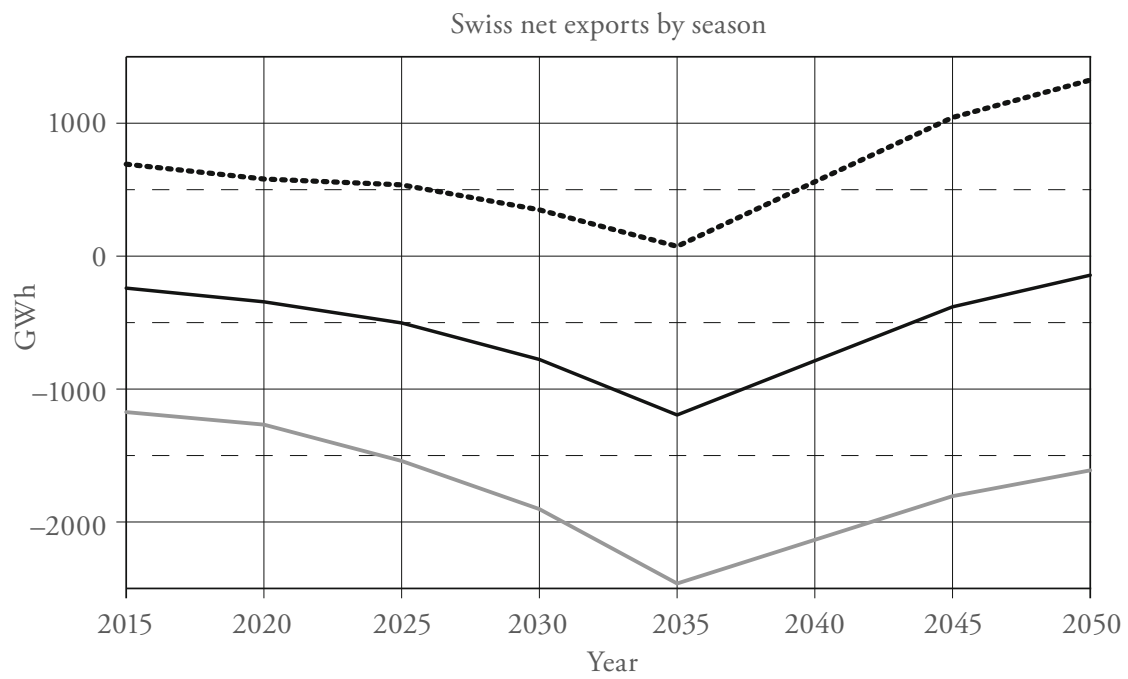

Timeframe: — Year —Winter .... Summer 
Switzerland as a transit country in-between is naturally impacted by those neighboring developments. However, given its large dependence on hydro power, its own nuclear phase-out schedule, and its increase in RES capacities, the crossborder situation clearly depicts these domestic trends. The hydro-dominated generation mix leads to net-export conditions during summer (hydro peaking months) and import-dependence during the winter months. This basic separation remains existent up to 2050 (Figure 3, lower panel). Up to 2035 the nuclear phase-out leads to a general decline in exports and a higher import dependency during the winter months. However, the increase in RES capacities compensates the phase-out effect on average till 2050. Nevertheless, the average balance exhibits larger seasonal deviations than the current system. During the summer months the high hydro generation coupled with increased solar generation leads to a significant increase of exports while during winter months the opposite effect leads to higher imports than under current conditions.

A striking trend in the hourly pattern of electricity flowing through Switzerland becomes obvious when comparing summer electricity flows on the ItalianSwiss border and the German-Swiss border in 2015 and 2050 (Figure 4). While in 2015 the afternoon solar peak still pushes from Germany towards the south, this hourly pattern changes completely to the opposite until 2050. By then, Italy's substantial own solar capacity, which benefits from the higher solar radiation and thus higher capacity factors, causes Italy to massively push electricity to Switzerland during solar peak hours while Germany is importing from Switzerland. Overall, the whole development of the flow pattern until 2050 in Central Europe during summer and to a lesser extent also in the winter is dominated by solar generation (see also Section 4.3.3).

Summarizing, the cross-border flow situation until 2050 exhibits significant shifts. Table 4 in Appendix III provides the specific values for all modeled border connections before netting. Besides the French-Swiss border flow that remains predominantly unidirectional, all other Swiss borders experience large import and export values during a year from 2030 onwards. This highlights the much higher variability in the whole system due to the increased share of intermittent generation.

Hydro power remains a driving element of the Swiss electricity market. In the last decades Swiss hydro energy, besides providing base-load capacity from runof-river plants, was a secure supply during noon and evening peak hours and pumped storage plants transferred nighttime electricity into the next day's peak hours. This picture is already altered by the current solar-driven price developments in Europe's electricity markets and will continue to transform up to 2050. As shown in Figure 5 the pumping times of Switzerland's hydro power plants 
Figure 4: Solar Power as Future Driving Factor of Swiss Border Balances in Summer.

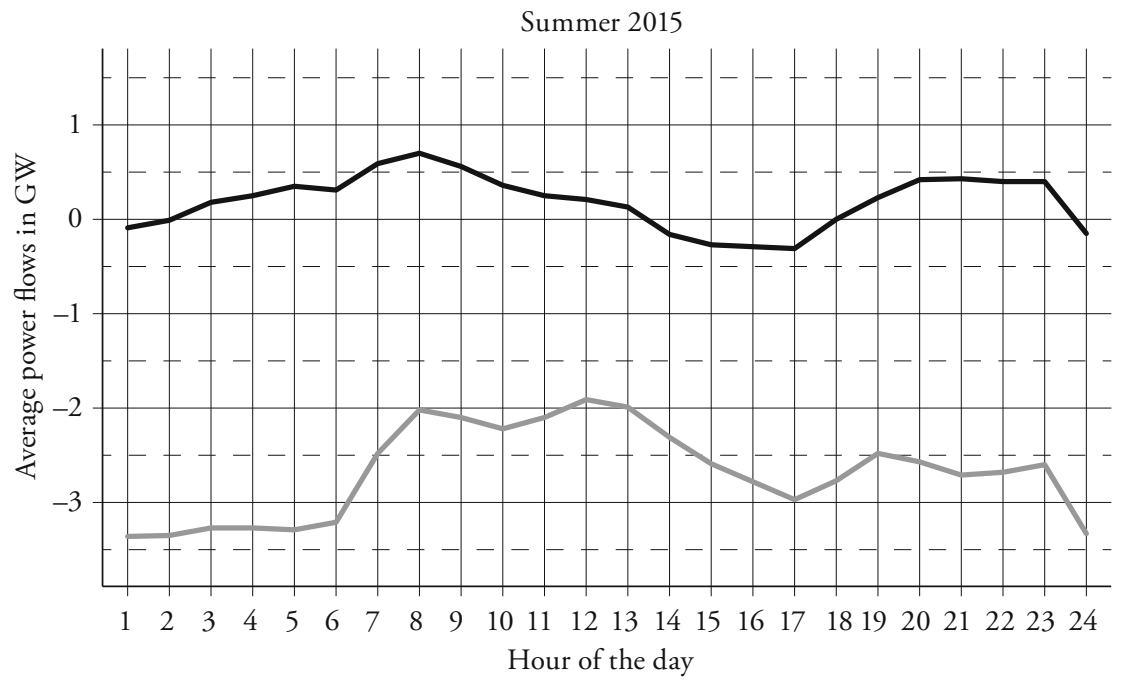

Flow direction: $\quad-\mathrm{CH} \rightarrow \mathrm{DE} \quad-\mathrm{IT} \rightarrow \mathrm{CH}$

Summer 2050

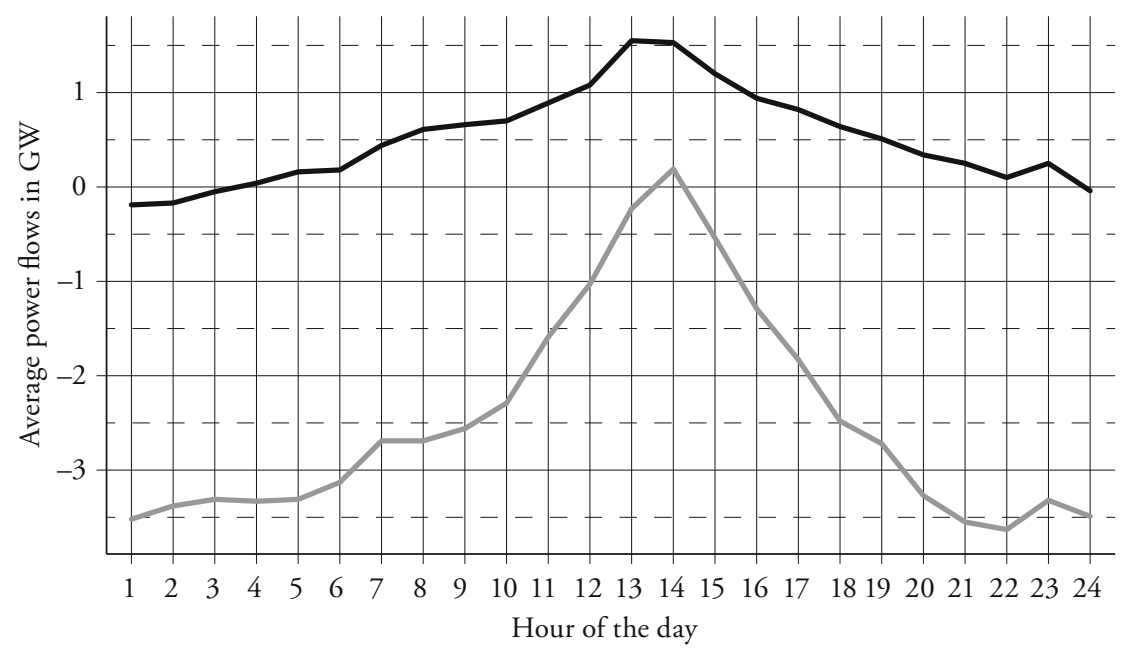


Figure 5: Sum of Hourly Pumped Electricity by Season.
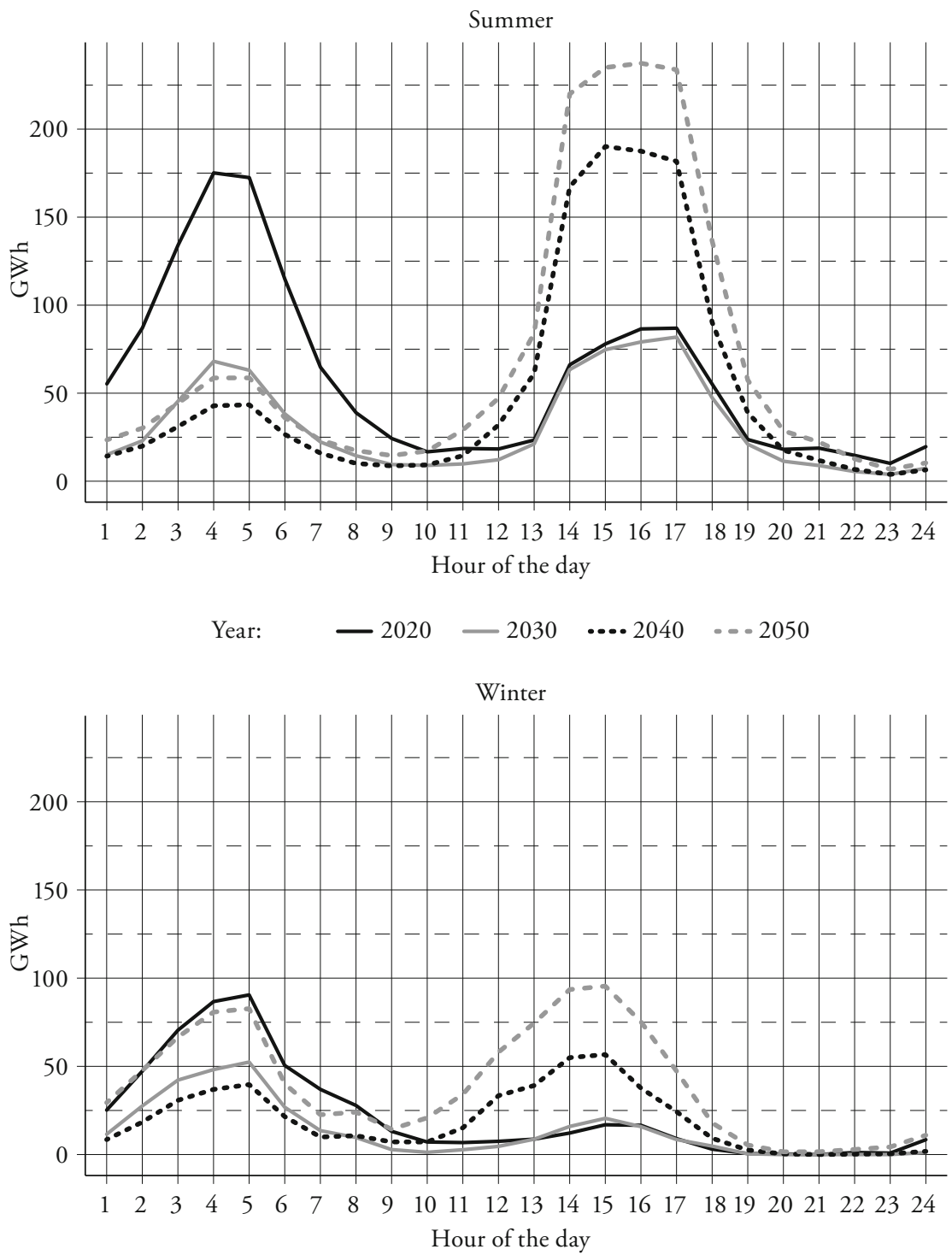
will move towards daytime hours when abundant solar generation is available. In turn, the stored energy will be utilized when RES capacities are insufficient to cover the demand levels, namely in the morning and evening hours. The nighttime hours remain an important storage time during the winter months but the majority of pump activity will be transferred to summer daytime.

Interestingly, despite its pumping activity during summer afternoons in 2050, Switzerland's summer exports also peak during precisely these afternoon hours. This is related to Switzerland's own solar capacities and the fact that hydro generation also peaks in summer, and pumping capacity not being large enough to absorb this surplus supply.

Albeit the changes in the daily pattern of pump operation are significant, the seasonal pattern remains largely unaffected. The stored energy is utilized within a few days and not transferred between seasons. This becomes obvious when examining the yearly storage level curve. The current pattern shows low storage levels in late winter months and the spring months and high levels following the Alpine snow melt in the late summer months. The pattern remains basically unchanged till $2050 .^{5}$ While the value of seasonal storage increases until 2050 given that in summer electricity supply will become more abundant than nowadays and in winter remains scarce, the system is restricted by the storage limits which remain unchanged in the scenarios and therefore cannot increase seasonal storage. ${ }^{6}$

\subsection{Overview on Delay Scenarios}

We now turn to the general results of the different delay scenarios. Table 2 provides an overview on the aggregated yearly costs and rents. ${ }^{7}$ Given that we assume a maximum delay of ten years and the TYNDP does not provide extensions for the later decades, from 2035 onwards all Swiss extensions will have been implemented and from 2040 onwards also all European extensions.

5 Note that we do not include temporal shifts on the water inflow side due to e.g. climate change effects.

6 Another reason for the limited seasonal storage is the price pattern in electricity. The price spread between hours with abundant RES injection and hours that require peaking fossil units will be the same in the short term either in summer or winter as in the long term. Consequently, using pumped storage to optimize between those hours on a short term basis is more efficient than only using it once to transfer energy between summer and winter.

7 We omit the result numbers of RES curtailment in the different scenarios as those values are below 2 TWh up to 2040 (less than $0.2 \%$ of total RES generation) and the impact of network delays on those numbers can be neglected. 
Consequently for later periods the results of the delay scenarios do not differ from the base case simulation.

Focusing on the overall impact on system welfare and generation costs the different delay scenarios lead to results as expected: with a later realization of network extensions more costly power plants need to be utilized to supply local demand in congested areas leading to an overall cost increase and welfare decrease. For the Swiss extensions the overall impact is rather modest with less than $50 \mathrm{~m}$ EUR per year of additional costs (less than $0.1 \%$ of total costs $\left.{ }^{8}\right)$. However, if the European extensions are delayed in the neighboring countries as well as the Swiss cross-border lines the overall costs increase by up to $700 \mathrm{~m}$ EUR per year (ca. $1.5 \%$ of total costs). Adding the inner-Swiss extension delay on top alters the total cost numbers by similar amounts as in the individual Swiss delay case. The total welfare effects are of similar absolute extents.

Given that we only model five-year time steps, the results indicate that a significant delay of the network extensions within the Swiss neighborhood alone is sufficient to add up several billions of Euros of cost burden. Compared to the total budget of the ENTSO-E TYNDP of about 150 bn EUR, of which only a fraction is covered within the modeled area, this represents a significant impact. Although model results always need to be taken with care, the simulations highlight the importance of cross-border network extensions for the European market and indicate potential high costs in case of prolonged delays. Nevertheless, in relation to the total electricity system costs the effects are still rather minor.

Examining the congestion situation within Switzerland we observe in general an increase in total congestion rent indicating that with delayed network extension price differences are more pronounced. ${ }^{9}$ This result is as expected given that the primary purpose of the extensions is to reduce the $n-1$ security issues and relieve network congestion. The differences between the Full Delay and the European Delay cases also highlight that, albeit cross-border lines are important drivers for Switzerland's electricity market, a large impact on the congestion situation is achieved by inner-country extensions.

8 Note that the total generation costs and the overall welfare figures include all modeled countries (AT, CH, DE, FR, IT). Furthermore, the absolute welfare amount is largely determined by the assumed demand elasticity. Consequently, we focus in the analysis on the costs, expenses and producer rents.

9 Note that our model calculates nodal prices for the Swiss transmission system whereas the current system is managed with a uniform market price and subsequent redispatching to match security constraints. Our results can be interpreted so that under the current system, extension delays require more interventions in the plant dispatch or other network measures to keep system security. 
Figure 6: Price Impact of Delay Scenarios.
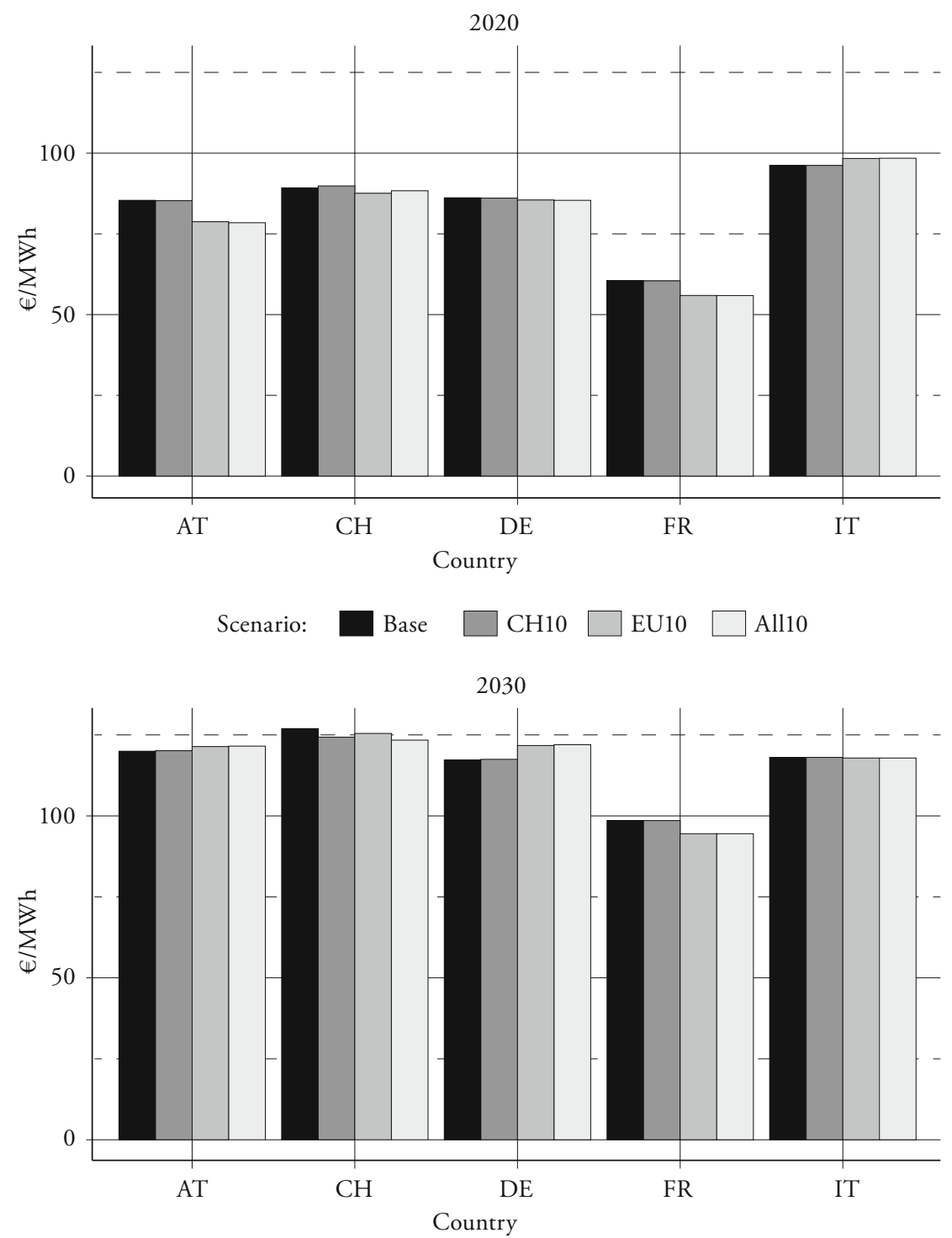
Turning to the other general results, the picture becomes less clear. In all cases we observe both negative and positive impacts on rents and consumer expenses. These effects are driven by the resulting price changes due to delayed network extension. Figure 6 shows this situation for the years 2020 and 2030. In 2020 the extension delay does not relieve the congestion between France and Italy as well as Austria and Italy. This leads to lower prices in the two exporting countries and slightly higher prices in Italy. As total demand and generation in France and Austria are larger than in Italy the lower consumer expenses and lower producer revenues in the former two countries over-compensate the increase in Italy leading to the negative impact of the delay (Table 2).

Table 2: Result Overview: Delay Scenarios.

\begin{tabular}{|c|c|c|c|c|c|c|c|c|}
\hline Base Case & 2015 & 2020 & 2025 & 2030 & 2035 & 2040 & 2045 & 2050 \\
\hline Welfare [bn] & 768 & 717 & 869 & 1100 & 1305 & 1468 & 1690 & 1891 \\
\hline Generation Costs [bn] & 45 & 42 & 47 & 58 & 67 & 72 & 80 & 83 \\
\hline Consumer Exp. [bn] & 135 & 127 & 151 & 190 & 222 & 251 & 287 & 314 \\
\hline Producer Rev. [bn] & 135 & 125 & 148 & 187 & 218 & 246 & 281 & 307 \\
\hline CH Congest. Rent $[\mathrm{m}]$ & 269 & 662 & 285 & 310 & 372 & 447 & 538 & 673 \\
\hline \multicolumn{9}{|l|}{$\mathrm{CH} 5$ y Delay } \\
\hline$\Delta$ Welfare $[\mathrm{m}]$ & 0.2 & -18.8 & -19 & & & & & \\
\hline$\Delta$ Cost $[\mathrm{m}]$ & -0.4 & 16.1 & 15.1 & & & & & \\
\hline$\Delta$ Expenses $[\mathrm{m}]$ & 2.6 & -33.4 & 10.1 & & & & & \\
\hline$\Delta$ Revenue $[\mathrm{m}]$ & 2.4 & -89.8 & 59.6 & & & & & \\
\hline$\Delta$ Cong. Rent $[\mathrm{m}]$ & 0.2 & 80.9 & 7.8 & & & & & \\
\hline \multicolumn{9}{|l|}{ EU 5y Delay } \\
\hline$\Delta$ Welfare $[\mathrm{m}]$ & - & -510.4 & -93.7 & -412.1 & & & & \\
\hline$\Delta$ Cost $[\mathrm{m}]$ & - & 667.6 & 68.8 & 307.5 & & & & \\
\hline$\Delta$ Expenses $[\mathrm{m}]$ & - & -2584 & -22.7 & 214.1 & & & & \\
\hline$\Delta$ Revenue $[\mathrm{m}]$ & - & -2517 & -188.4 & 115.5 & & & & \\
\hline$\Delta$ Cong. Rent $[\mathrm{m}]$ & - & -3.6 & 26.4 & 21.8 & & & & \\
\hline
\end{tabular}


Table 2 continued

\begin{tabular}{|c|c|c|c|c|c|c|c|c|}
\hline Base Case & 2015 & 2020 & 2025 & 2030 & 2035 & 2040 & 2045 & 2050 \\
\hline \multicolumn{9}{|l|}{ All 5y Delay } \\
\hline$\Delta$ Welfare $[\mathrm{m}]$ & 0.2 & -530.7 & -105.2 & -412.1 & & & & \\
\hline$\Delta$ Cost $[\mathrm{m}]$ & -0.4 & 683.1 & 83.1 & 307.5 & & & & \\
\hline$\Delta$ Expenses $[\mathrm{m}]$ & 2.6 & -2584 & -58.6 & 214.1 & & & & \\
\hline$\Delta$ Revenue $[\mathrm{m}]$ & 2.4 & -2566 & -157.8 & 115.5 & & & & \\
\hline$\Delta$ Cong. Rent $[\mathrm{m}]$ & 0.2 & 54.3 & 39.7 & 21.8 & & & & \\
\hline \multicolumn{9}{|l|}{$\mathrm{CH}$ 10y Delay } \\
\hline$\Delta$ Welfare $[\mathrm{m}]$ & 0.2 & -20.6 & -35.7 & -27.7 & & & & \\
\hline$\Delta$ Cost $[\mathrm{m}]$ & -0.4 & 17.6 & 23.1 & 43.5 & & & & \\
\hline$\Delta$ Expenses $[\mathrm{m}]$ & 2.6 & -41.3 & 29.3 & -49.5 & & & & \\
\hline$\Delta$ Revenue $[\mathrm{m}]$ & 2.4 & -112.4 & 38.3 & 101.8 & & & & \\
\hline$\Delta$ Cong. Rent $[\mathrm{m}]$ & 0.2 & 90 & 52.4 & 15.6 & & & & \\
\hline \multicolumn{9}{|l|}{ EU 10y Delay } \\
\hline$\Delta$ Welfare $[\mathrm{m}]$ & - & -510.4 & -413.2 & -536.2 & -494.5 & & & \\
\hline$\Delta$ Cost $[\mathrm{m}]$ & - & 667.6 & 406.8 & 390.1 & 433 & & & \\
\hline$\Delta$ Expenses $[\mathrm{m}]$ & - & -2583 & -938.2 & 305.2 & -345.3 & & & \\
\hline$\Delta$ Revenue $[\mathrm{m}]$ & - & -2517 & -1102 & 33.8 & -419.2 & & & \\
\hline$\Delta$ Cong. Rent $[\mathrm{m}]$ & - & -3.6 & 38.4 & 55.8 & 29.2 & & & \\
\hline \multicolumn{9}{|l|}{ All 10y Delay } \\
\hline$\Delta$ Welfare $[\mathrm{m}]$ & 0.2 & -532.8 & -434.3 & -554.7 & -494.5 & & & \\
\hline$\Delta$ Cost $[\mathrm{m}]$ & -0.4 & 684.6 & 439 & 407.8 & 433 & & & \\
\hline$\Delta$ Expenses $[\mathrm{m}]$ & 2.6 & -2592 & -1073 & 309.6 & -345.3 & & & \\
\hline$\Delta$ Revenue $[\mathrm{m}]$ & 2.4 & -2589 & -1152 & 99.3 & -419.2 & & & \\
\hline$\Delta$ Cong. Rent $[\mathrm{m}]$ & 0.2 & 59.2 & 91.6 & 65.2 & 29.2 & & & \\
\hline
\end{tabular}

Note: $\Delta=$ changes relative to base case in million Euro 
In 2030 the situation is altered as the extension delay mostly impacts the French and German price levels, again with France facing lower prices. However, as Germany has higher demand and generation totals the price increase in Germany over-compensates the decrease in France leading to a positive impact on expenses and producer rent (Table 2). We will analyze these national effects in more detail in the following section.

\subsection{Detailed Impacts of Network Extension Delay}

Given the large amount of different scenario results, we highlight general trends and insights in the following sections.

\subsubsection{National Price Impacts and the Winner and Loser Problem}

As already shown in the general results section the impact of the different delay cases on producer rents and consumer expenses varies depending on the underlying price changes. This is a normal result if transport capacities between regions with different price levels are altered. If existing congestion is reduced this normally leads to a price convergence between the connected regions and thereby higher prices in the exporting region and lower prices in the importing region. This effect can also be observed in the different delay scenarios. Table 3 shows this for the ten-year Swiss and Full delay cases for the 2020 and 2030 time slices. In the 2020 Swiss delay we observe a slight price decrease in the exporting countries France, Germany, and Austria and slight increases in import-dependent Italy with respective changes in the net import levels. In the 2030 setting we observe an altered market situation for Germany, Italy, and Austria facing slightly higher prices due to the changed import-export pattern (see Section 4.3.4 for details) while Switzerland and France face lower prices due to the extension delay.

In case of a full extension delay the missing cross-border lines lead to significant changes in the energy balances of the modeled countries. In general France faces lower prices and lower exports leading to reduced producer rents in France but simultaneously lower consumer expenses. In 2020 it is Italy that faces higher prices and is subsequently forced to rely on more costly domestic production. In 2030 this role is reserved for Germany. This also explains the difference in the overall expenses and rents in the two settings (Table 2) as explained in the previous section.

Beside the national changes for consumers and producers, also the changed import/export values will lead to changes in national rents. As the network owners or system operators will collect the respective rents on cross-border connections, a reduction in cross-border flows as well as a change in the price difference between 
countries will alter the income; i.e. given the increased price spread between France and its import countries, the actual collected cross-border rent in France increases in most scenarios despite the reduced export volume while the collected rent on the Swiss border declines. Given that the network will remain a regulated part of electricity markets, the impact of the income change will depend on the regulatory design.

Table 3: Changes in Comparison to Base Case on Country Level.

\begin{tabular}{|c|c|c|c|c|c|}
\hline & $\mathrm{CH}$ & $\mathrm{DE}$ & AT & IT & FR \\
\hline & & & 2020 & & \\
\hline \multicolumn{6}{|l|}{$\mathrm{CH} 10 y$ delay } \\
\hline Price [EUR/MWh] & 0.59 & -0.1 & -0.12 & 0.07 & -0.09 \\
\hline BorderCongRent [mEUR] & -1 & -2 & -2 & 7 & 13 \\
\hline NetImport [GWh] & -154 & 285 & 51 & -456 & 274 \\
\hline Generation [GWh] & -625 & -181 & 44 & 398 & 142 \\
\hline \multicolumn{6}{|l|}{ All 10y delay } \\
\hline Price [EUR/MWh] & -0.91 & -0.78 & -6.94 & 2.23 & -4.65 \\
\hline BorderCongRent [mEUR] & -42 & 52 & 48 & 162 & 230 \\
\hline NetImport [GWh] & 74 & 4911 & 1620 & -13566 & 6962 \\
\hline \multirow[t]{2}{*}{ Generation [GWh] } & -252 & -2862 & -2292 & 11199 & 830 \\
\hline & \multicolumn{5}{|c|}{2030} \\
\hline \multicolumn{6}{|l|}{ CH 10y delay } \\
\hline Price [EUR/MWh] & -2.63 & 0.19 & 0.16 & 0.11 & -0.03 \\
\hline BorderCongRent [mEUR] & -43 & 9 & 4 & -5 & 13 \\
\hline NetImport [GWh] & 205 & -395 & -35 & -530 & 755 \\
\hline Generation [GWh] & 315 & 398 & 92 & 352 & -462 \\
\hline \multicolumn{6}{|l|}{ All 10y delay } \\
\hline Price [EUR/MWh] & -3.56 & 4.7 & 1.58 & -0.2 & -4.09 \\
\hline BorderCongRent [mEUR] & -30 & 230 & 1 & 49 & 234 \\
\hline NetImport [GWh] & 350 & -10415 & -303 & 991 & 9377 \\
\hline Generation [GWh] & 795 & 7524 & -803 & -797 & -4220 \\
\hline
\end{tabular}


This highlights the classical problem of winners and losers in such settings. As price changes have different effects on consumers, producers, and traders an altered import-export setting with subsequent price adjustments can easily lead to large shifts in rents. This is complicated in electricity networks as the actual transmission is heavily influenced by the dispatch which in turn is increasingly impacted by volatile RES injections. The switch of Italy from an import-dependent country in 2020 towards a more exchange-balanced country in 2030 highlights this development. Such changes in turn can easily influence the incentives for a country to pursue delayed network projects which may benefit another country or the overall system.

\subsubsection{Shifting Flow Patterns and the Impact of Bottlenecks}

An interesting result of the scenario runs regards the timing of investments along a flow path. In pre-runs with a slightly different network configuration we obtained positive cost effects if the inner-Swiss extensions are delayed; meaning that a delay would be beneficial for the system. In the final model runs we altered the switching status of a congested connection between Switzerland and Italy that prevents this effect. ${ }^{10}$ Only in the 2015 time slice the impact can still be observed with a slight increase in welfare and a lower cost level in case of delayed extensions in Switzerland (Table 2).

On a first glance this effect seems counter-intuitive. Extending the network should allow for more transmission and thereby always be beneficial for the total system, given that we do not include investment costs in our welfare and cost analysis. However, electricity flows follow physical laws and altering the network characteristics by extending specific lines also alters how flows distribute along specific paths. Switzerland as a central hub between exporting and importing countries will have a large impact on this flow pattern when it extends its network. The innerSwiss capacity extensions reduce the relative resistance on the path via Switzerland and thereby will cause more energy flows on these routes. If a bottleneck at the beginning or at the end of this path, outside of Switzerland, now prevails, the actual resulting transmission pattern will be more restricted than before the extension. ${ }^{11}$

10 Note that within Swissmod all lines connected to a node are connected with each other, while in the real transmission system the specific switching status at nodes can be adjusted to only connect specific sub-sets of lines with each other.

11 This is based on the combination of series and parallel circuits in meshed electricity systems that, combined with the daily and seasonal fluctuations within demand and generation, sometimes obfuscate what the resulting optimal investment pattern should be. An example and general explanation that the strengthening of a line can lead to higher overall system costs is provided in Wu et al. (1996). 
A non-electricity analogy could be seen in the European highway system. If Switzerland extends its highways from two to three lanes it attracts transit traffic from the North-South routes of France and Austria. If the Italian highways following the Swiss border represent the bottleneck in this system and are not extended as well, the congestion situation is actually worse afterwards. Albeit altering the switching status of the system can help to relieve these effects, in reality the results hint to the important role of international coordination in electricity transmission. Especially, Switzerland as a transit country needs to account for the extensions within its neighboring countries. In extreme cases it may even be advisable to voluntarily delay inner-Swiss extensions if it becomes obvious that the delay in relieving a bottleneck along the path outside of the Swiss system will lead to overall worsened system conditions.

\subsubsection{Impact on Swiss Electricity Market and the Energy Transition}

The impacts of the delayed network extensions on the Swiss electricity market are rather modest in terms of changes in dispatch and prices. This is naturally an effect of the considered time frame of the delays. Given that we only account for the planned extension within the next ten years and account for a maximum delay of ten years, the network from 2035 on is similar in all scenarios. However, the large changes in the Swiss market occur after 2035; i.e. the shift from nuclear towards RES-based generation. ${ }^{12}$ Naturally, the delay does not impact this development and most effects occur due to changes in the European market interactions.

In most scenarios the price level is slightly lower due to the delay as the export options remain limited and keep national price differences more pronounced with Switzerland on the lower price end. In case of an inner-Swiss delay the hydro output is slightly lower due to reduced pumping activity. In case of a delay in the European system the reverse effect occurs and in the full delay cases a mix of both effects can be observed. Nevertheless, the profit for Swiss hydro operators decreases in nearly all scenarios by about $1-2 \%$. This is mostly induced by the lower price level and consequent slightly lower price spreads that reduce the overall profit even in those scenarios that have higher pumping activity.

The major impact of the delays is not surprisingly on the European power flow patterns and thereby the flows into and out of Switzerland. Albeit the impact on the Swiss import-export flows on the individual borders is quite pronounced the

12 Whether further network extensions from 2035 onwards can further support the transition is not part of the analysis. 
Figure 7: Changes in Import and Export Patterns [GWh].
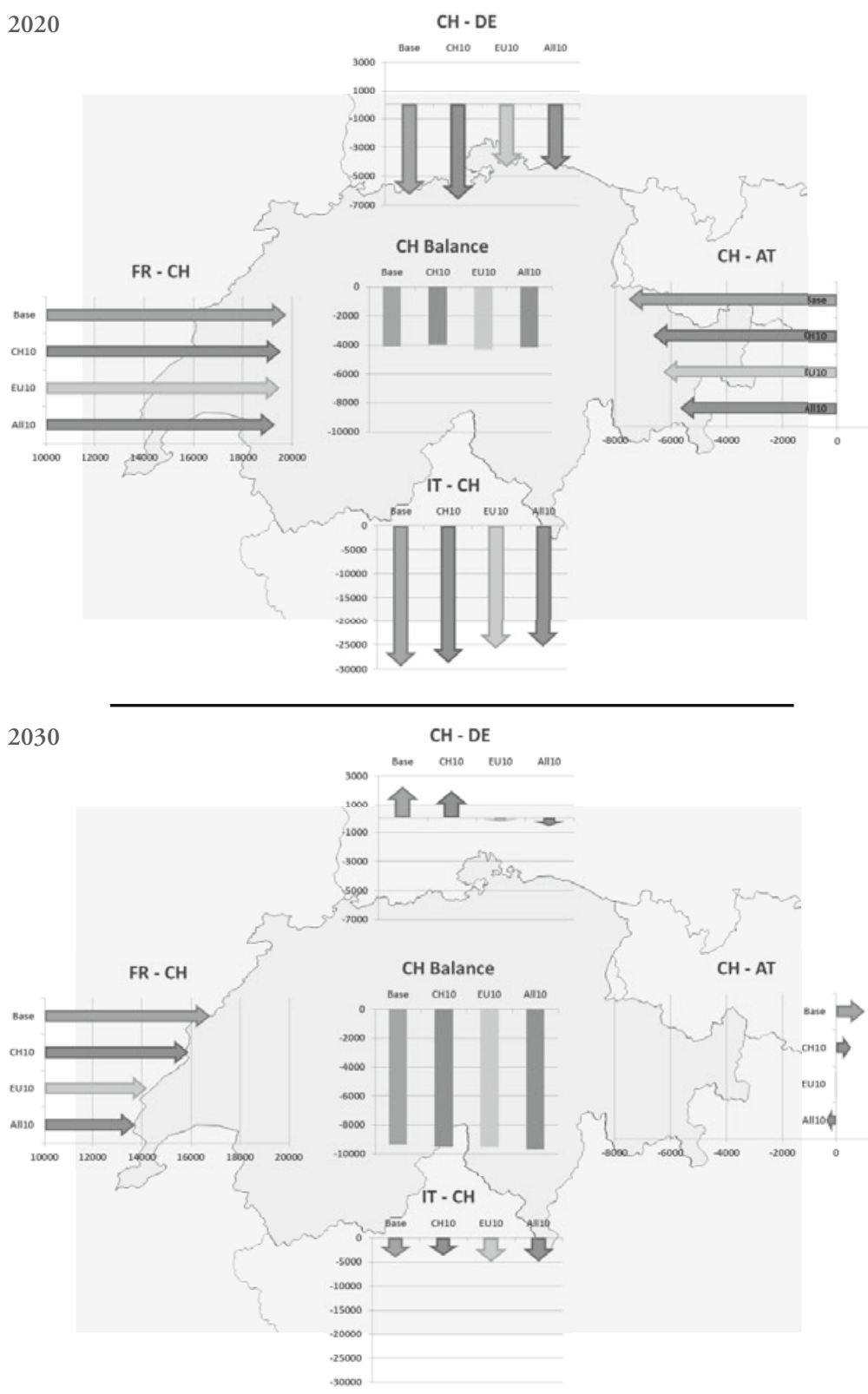
overall impact on the net balance of Switzerland is minor in most cases. Figure 7 highlights this effect for the years 2020 and 2030. The figure also highlights the major shift in European flow patterns over time due to changed dispatch conditions. In 2020 Switzerland still mainly acts as transition hub for electricity flowing towards Italy. An extension delay leads to reduced imports from France, Germany, and Austria and respective reduced exports towards Italy, keeping the overall Swiss balance on a similar level.

In 2030 the overall pattern is altered by the increase in RES capacities in Italy $(+10 \mathrm{GW}$ of wind and solar compared to 2020 , respectively) and the final phaseout of nuclear in Germany (-7GW compared to 2020). Switzerland thereby also becomes a transit hub for French electricity for the German market. In addition, the nuclear phase-out in Switzerland reduces the available domestic production while new RES capacities are still rather minor. This leads to a higher import dependency with a respective net balance of ca. 9TWh per year. Again, the different delay scenarios lead to significant changes on the individual borders; particular on the German and Austrian border we can observe a reverse of the average flow direction. However, the Swiss net balance is basically unaltered.

Summarizing, the impact on Switzerland is focused on network related aspects. The timeframe of the Swiss energy transition with a large focus on RES integration from 2035 onwards is unaffected by a delay of the currently planned extensions as long as it remains in the analyzed boundaries of ten years.

\section{Conclusion}

In this paper, we analyze the role of the Swiss transmission system for the future development of the Central European energy markets and evaluate the impact of extension delays on this development. Using a network model of the Swiss electricity market and its neighboring markets Swissmod we first simulate the expected market developments to 2050 based on the Swiss Energy Strategy 2050 and the EU Energy Roadmap. Second, we derive different scenarios with delays in the expected network extensions up to ten years.

To sum up, our base case simulations show a gradual price increase until 2050 based on the assumed significant increase in emission allowance prices and the fact that fossil plants are still the marginal price setting units in many hours, a continued strong export position of France and a decline of Italy's importdependence, and a significant shift in power flow patterns due to the increased renewable generation with a particular strong linkage to the typical daily solar 
injection pattern. These developments lead to changes in the import-export flows across Switzerland, albeit the average balanced net position with an exporting role in summer and importing role in winter persists. The results also show that the planned extension projects of ENTSO-E's Ten Year Network Development Plan (TYNDP) reduce congestion within the system and help to exchange electricity from fluctuating renewable energy sources across Central Europe. Thus our results are in line with the analyses of Consentec (2012a) and Singh et al. (2014) with respect to the expected network developments.

The different delay scenarios naturally lead to shifts in the import-export balances, with generally less price convergence and fewer cross-border flows. France on average faces lower exports and Italy and Germany lower imports. Flows through Switzerland as a transit country are affected accordingly, albeit its netbalance does not change. As the extensions are aimed at reducing existing congestion the delay leads to higher generation costs in Europe of up to 700 million EUR per year. Albeit this amount represents only a few percentage points of total generation costs in Central Europe, the total extent still highlights the importance of a fast network extension to improve cross-regional energy exchange.

Overall, the simulation results highlight the importance of cross-border coordination in electricity transmission. As changes within one country's transmission system impact and are impacted by power flows in neighboring countries, joint evaluations of potential extension projects and also a coordinated realization will benefit the overall system. The ongoing ENTSO-E network development and the EU regulation 347/2013 on trans-European energy infrastructure are important elements of such coordination.

A second important coordination aspect in electricity markets is the interaction between generation and transmission investments. The model results show the impact of a delayed network extension but due to the model structure do not capture the feedback effect on plant investments. How to coordinate competitive market investments on the generation side with the regulated investment frameworks in transmission in a European framework is still an open issue.

For the Swiss electricity market both the general developments as well as the impact of extension delays are relatively uncritical with respect to the Energy Strategy 2050. The major shift from nuclear towards renewable generation is assumed to occur after 2035 and is thereby not impacted by a delay within the next decade. Similarly, the central position and the large import and export capacities allow Switzerland to compensate any local shortfall with increased imports. Nevertheless, the planned extensions are needed to relieve existing bottlenecks and congestion within the system and a delay will lead to additional costs in keeping the system stable. Similarly, the change in cross-border flows will result in 
changed revenues for the Swiss system operator. Whereas the delay will lead to a decline in earnings, the long-term developments lead to an increase in revenues.

\section{Appendix I: Model}

$\begin{array}{ll}\text { Endogenous Variables } & \\ D & \text { Demand } \\ F & \text { Power flow } \\ G & \text { Generation } \\ P(D) & \text { Inverse demand Function } \\ Q & \text { Pumping electricity } \\ R & \text { Welfare (rents) } \\ W \downarrow, W \uparrow & \text { Water discharged, pumped } \\ W I, W O & \text { Water inflow, outflow } \\ S, \Delta S & \text { Storage content, addition } \\ \vec{W} & \text { Water flowing to next node } \\ X & \text { Phase angle difference }\end{array}$

\section{Parameters}

$\begin{array}{ll}\bar{g}, \bar{q} & \text { Limits of generation, pumping } \\ \bar{f} & \text { Line flow limit } \\ \bar{s} & \text { Storage limit } \\ b & \text { Power line susceptance } \\ v c, \hat{v} c & \text { Variable cost intercept, slope } \\ \alpha & \text { Production equivalent } \\ \beta & \text { Pumping efficiency factor } \\ \dot{w} & \text { Local inflow to water node } \\ \dot{e} & \text { Renewables in-feed }\end{array}$

Indices / Sets

$\begin{array}{ll}n \in N & \text { Power nodes } \\ l \in L & \text { Power lines } \\ t \in T & \text { Time periods } \\ c p \in C P & \text { Conventional plants } \\ h p \in H P & \text { Hydropower plants } \\ w n, u w n, l w n \in W N & \text { Water nodes (upper, lower) }\end{array}$




\section{Matrices}

$\begin{array}{ll}i_{l, n} & \text { Power grid incidence } \in\{0,1,-1\} \\ c p i_{c p}^{n} & \text { Conv. plant incidence } \in\{0,1\} \\ h p i_{h p}^{n} & \text { Hydro plant incidence } \in\{0,1\} \\ u p r_{h p}^{w n} & \text { Plant upper water node } \in\{0,1\} \\ l w r_{h p}^{w n} & \text { Plant lower water node } \in\{0,1\} \\ \theta_{l w n}^{\text {uwn }} & \text { Water node successor matrix } \in\{0,1\} \\ z_{l w n}^{\text {uwn }} & \text { Water delay time } \in N\end{array}$

Objective Function $\max R=\sum_{t, n} \int_{0}^{D_{n, t}} P_{n, t}\left(D_{n, t}\right) d D_{n, t}-\sum_{t, c p} G_{t}^{c p}\left(v c^{c p}+\hat{v} c^{c p} G_{t}^{c p}\right)$

Power flow $\quad F_{t}^{l}=b^{l} \sum_{n} i_{l, n} X_{t}^{n}$

Fixing the slack bus $X_{t}^{n 1}=0$

Power node balance $\sum_{l} i_{l, n} F_{t}^{l}=\sum_{c p} c p i_{c p}^{n} G_{t}^{c p}+\sum_{h p} h p i_{h p}^{n}\left(G_{t}^{h p}-Q_{t}^{h p}\right)+\dot{e}_{n}-D_{n, t}$

Maximum line flow $-\bar{f}^{l} \leq F_{t}^{l} \leq \bar{f}^{l}$

Plant capacity limit $\quad G_{t}^{c p} \leq \bar{g}^{c p}$

$\forall c p, t$

Discharge function $\quad G_{t}^{h p}=\alpha^{h p} W \downarrow_{t}^{h p}$ $\forall h p, t$

Pumping function $\quad Q_{t}^{h p}=\alpha^{h p} W \uparrow_{t}^{h p} / \beta^{h p}$ $\forall h p, t$

Discharge capacity $\quad G_{t}^{h p} \leq \bar{g}^{h p}$ $\forall h p, t$

Pumping capacity $\quad Q_{t}^{h p} \leq \bar{q}^{-h_{p}}$ $\forall h p, t$

Water node inflow $\quad W I_{t}^{w n}=\dot{w}_{t}^{w n}+\sum_{h p}\left(l w r_{h p}^{w n} W \downarrow_{t}^{h p}+u p r_{h p}^{w n} W \uparrow_{t}^{h p}\right)+\sum_{u w n} \theta_{w n}^{u w n} \vec{W}_{t-z_{w n}^{u w n}}^{\text {uwn }}$

Water node outflow $W O_{t}^{w n}=\sum_{h p}\left(u p r_{h p}^{w n} W \downarrow_{t}^{h p}+l w r_{h p}^{w n} W \uparrow_{t}^{h p}\right)+\sum_{l w n} \theta_{l w n}^{w n} \vec{W}_{t}^{w n}$

$\forall w n, t$

Storage changes

$$
\Delta S_{t}^{w n}=S_{t}^{w n}-S_{t-1}^{w n}
$$




\section{Appendix II: Linear demand function}

We modify the original Swissmod model (Schlecht and Weigt, 2014) by assuming a linear elastic demand function rather than a fixed constant load in order to maximize welfare instead of minimizing cost.

To derive the specification we use in the model we follow Leuthold et al (2012) and assume a linear inverse demand function $P_{n, t}\left(D_{n, t}\right)$ as given in Eq. 1 with the slope $M \leq 0$ and intercept $A \geq 0$. Rearranging yields the demand function Eq. 2 while Eq. 3 displays the standard equation for calculating the price elasticity of demand.

$$
\begin{gathered}
P_{n, t}=A+M D_{n, t} \\
D_{n, t}=-\frac{A}{M}+\frac{1}{M} P_{n, t} \\
\varepsilon=\frac{\partial D_{n, t}}{\partial P_{n, t}} \frac{P_{n, t}}{D_{n, t}}=\frac{P_{n, t}}{M D_{n, t}}
\end{gathered}
$$

In order to derive the prohibitive price $A$ and slope $M$, we assume a known demand elasticity $\varepsilon=0.1$ to hold at reference points $\left(p_{n, t}^{\text {ref }}, d_{n, t}^{\text {ref }}\right)$. We assume these reference quantities to be historical demand values (scaled to future expected yearly demand levels), and reference prices to be the yearly average prices we get from prior cost minimization runs of the model.

The prohibitive price $A$ and slope $M$ for each node $n$ and time period $t$ can thus be calculated on the basis of the given reference values for price and demand according to Eqs. 4 and 5.

$$
\begin{gathered}
M=\frac{p_{n, t}^{r e f}}{d_{n, t}^{r e f}} \frac{1}{\varepsilon} \\
A=p_{n, t}^{r e f}-M d_{n, t}^{r e f}=\left(1-\frac{1}{\varepsilon}\right) p_{n, t}^{r e f}
\end{gathered}
$$

Inserting Eqs. 4 and 5 into 1 yields 6 which is the equation that is used in the model to determine the linear inverse demand functions per node $n$ and time period $t$. 


$$
P_{n, t}=p_{n, t}^{r e f}-\frac{p_{n, t}^{r e f}}{M d_{n, t}^{r e f}} \frac{1}{\varepsilon} d_{n, t}^{r e f}+\frac{p_{n, t}^{r e f}}{M d_{n, t}^{r e f}} \frac{1}{\varepsilon} D_{n, t}=p_{n, t}^{r e f}+\frac{1}{\varepsilon} p_{n, t}^{r e f}\left(\frac{D_{n, t}}{d_{n, t}^{r e f}}-1\right)
$$

\section{Appendix III: Detailed Cross Border Flows}

Table 4: Detailed Cross-Border Flows in GWh per Year.

\begin{tabular}{|c|c|c|c|c|c|c|}
\hline & & $\mathrm{CH}$ & $\mathrm{DE}$ & AT & IT & FR \\
\hline \multirow{5}{*}{$\stackrel{n}{\stackrel{n}{\sim}}$} & $\mathrm{CH}$ & - & 2831 & 641 & 22821 & 223 \\
\hline & $\mathrm{DE}$ & 6420 & - & 8571 & - & 2522 \\
\hline & AT & 5405 & 4087 & - & 1177 & - \\
\hline & IT & 1812 & - & 67 & - & 1065 \\
\hline & FR & 15764 & 7244 & - & 17695 & - \\
\hline \multirow{5}{*}{ ڤ્ડે } & $\mathrm{CH}$ & 0 & 1362 & 176 & 31291 & 140 \\
\hline & $\mathrm{DE}$ & 7666 & 0 & 12554 & 0 & 1122 \\
\hline & AT & 7702 & 6186 & 0 & 3790 & 0 \\
\hline & IT & 1798 & 0 & 27 & 0 & 176 \\
\hline & FR & 19921 & 7861 & 0 & 28776 & 0 \\
\hline \multirow{5}{*}{ ণి } & $\mathrm{CH}$ & 0 & 6787 & 4260 & 17440 & 891 \\
\hline & $\mathrm{DE}$ & 4482 & 0 & 10253 & 0 & 974 \\
\hline & AT & 3248 & 14899 & 0 & 2537 & 0 \\
\hline & IT & 13276 & 0 & 1641 & 0 & 5202 \\
\hline & FR & 17695 & 15445 & 0 & 18222 & 0 \\
\hline \multirow{5}{*}{ 市 } & $\mathrm{CH}$ & 0 & 7619 & 5648 & 14431 & 1329 \\
\hline & $\mathrm{DE}$ & 3648 & 0 & 7894 & 0 & 571 \\
\hline & AT & 2045 & 16829 & 0 & 2062 & 0 \\
\hline & IT & 16102 & 0 & 2214 & 0 & 6505 \\
\hline & FR & 16675 & 17811 & 0 & 16283 & 0 \\
\hline \multirow{5}{*}{ iิ } & $\mathrm{CH}$ & 0 & 4733 & 2759 & 23377 & 1562 \\
\hline & $\mathrm{DE}$ & 5336 & 0 & 11711 & 0 & 1127 \\
\hline & AT & 3631 & 10848 & 0 & 3333 & 0 \\
\hline & IT & 8209 & 0 & 942 & 0 & 3501 \\
\hline & FR & 16969 & 15813 & 0 & 20922 & 0 \\
\hline
\end{tabular}

Source country on vertical axis, destination country on horizontal axis. 


\section{Appendix IV: Grid extension projects}

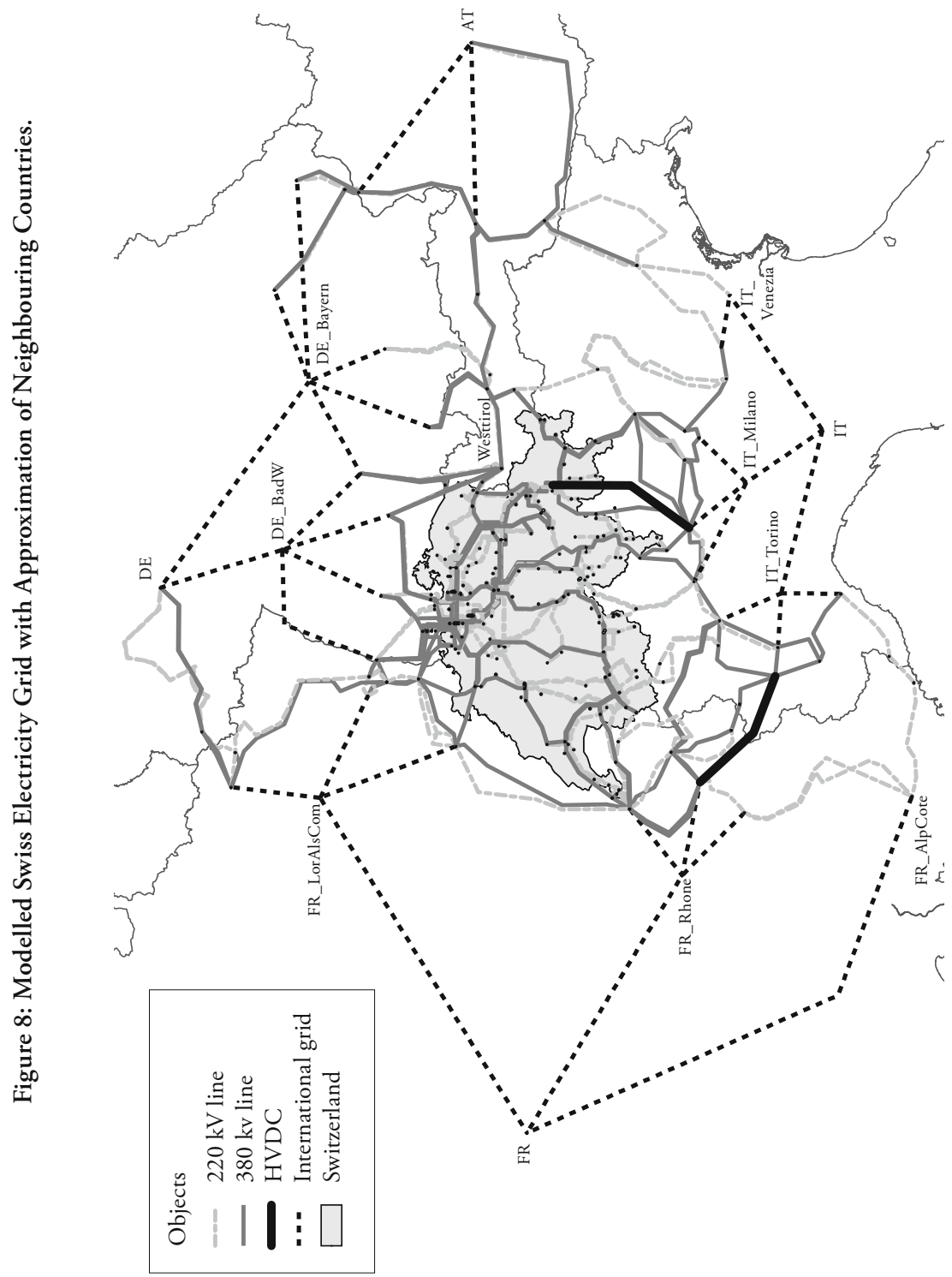


Table 5: Extension Projects Included in the Model.

\begin{tabular}{|c|c|c|c|c|c|c|}
\hline $\begin{array}{l}\text { ENTSOE } \\
\text { Project } \\
\text { Index }\end{array}$ & Substation 1 & Substation 2 & $\begin{array}{c}\text { ENSTOE } \\
\text { expected } \\
\text { year }\end{array}$ & $\begin{array}{l}\text { Base } \\
\text { case } \\
\text { year }\end{array}$ & $\begin{array}{l}\text { New } \\
\text { or } \\
\text { Upg. }\end{array}$ & Target type \\
\hline \multicolumn{7}{|l|}{ Switzerland } \\
\hline \multirow[t]{2}{*}{91.121} & Bickigen & Chippis & 2020 & 2025 & $\mathrm{U}$ & $\begin{array}{c}1 \times 380 \mathrm{kV} \\
+1 \times 220 \mathrm{kV}\end{array}$ \\
\hline & Chippis & Chamoson & 2020 & 2020 & $\mathrm{U}$ & $\begin{array}{c}2 \times 380 \mathrm{kV} \\
+1 \times 220 \mathrm{kV}\end{array}$ \\
\hline \multirow[t]{4}{*}{91.122} & Chippis & Mörel & 2020 & 2025 & $\mathrm{U}$ & $2 \times 380 \mathrm{kV}$ \\
\hline & Chippis & Stalden & 2020 & 2020 & $\mathrm{U}$ & $220 \mathrm{kV}$ \\
\hline & Mörel & Ulrichen & 2020 & 2025 & $\mathrm{U}$ & $1 \times 380 \mathrm{kV}$ \\
\hline & Airolo & Lavorgo & 2020 & 2025 & $\mathrm{U}$ & $2 \times 380 \mathrm{kV}$ \\
\hline \multirow[t]{4}{*}{90.134} & Bassecourt & Mühleberg & 2020 & 2020 & $\mathrm{U}$ & $\begin{array}{c}1 \times 380 \mathrm{kV} \\
+1 \times 132 \mathrm{kV}\end{array}$ \\
\hline & Mühleberg & Galmiz & 2020 & 2025 & $\mathrm{U}$ & $\begin{array}{c}1 \times 380 \mathrm{kV} \\
+1 \times 220 \mathrm{kV}\end{array}$ \\
\hline & Galmiz & Mathod & 2020 & 2025 & $\mathrm{~N}$ & $2 \times 380 \mathrm{kV}$ \\
\hline & Mathod & Romanel & 2020 & 2020 & $\mathrm{U}$ & $\begin{array}{c}1 \times 380 \mathrm{kV} \\
+1 \times 220 \mathrm{kV}\end{array}$ \\
\hline \multirow[t]{4}{*}{90.129} & Beznau & Birr & 2020 & 2020 & $\mathrm{U}$ & $2 \times 380 \mathrm{kV}$ \\
\hline & Birr & Niederwil & 2020 & 2020 & $\mathrm{U}$ & $\begin{array}{c}1 \times 380 \mathrm{kV} \\
+1 \times 220 \mathrm{kV}\end{array}$ \\
\hline & Niederwil & Obfelden & 2020 & 2025 & $\mathrm{U}$ & $2 \times 380 \mathrm{kV}$ \\
\hline & Obfelden & Mettlen & 2020 & 2025 & $\mathrm{U}$ & $2 \times 380 \mathrm{kV}$ \\
\hline \multirow[t]{3}{*}{91.128} & Chamoson & Romanel & 2020 & 2020 & $\mathrm{U}$ & $2 \times 380 \mathrm{kV}$ \\
\hline & Conn. N. de Drance & & 2020 & 2020 & $\mathrm{~N}$ & $2 \times 380 \mathrm{kV}$ \\
\hline & Conn. Chavalon & & 2020 & 2020 & $\mathrm{U}$ & $2 \times 380 \mathrm{kV}$ \\
\hline \multirow[t]{2}{*}{91.123} & Mettlen & Innertkirchen & 2019 & 2025 & $\mathrm{U}$ & $2 \times 380 \mathrm{kV}$ \\
\hline & Innertkirchen & Ulrichen & 2019 & 2025 & $\mathrm{U}$ & $\begin{array}{c}1 \times 380 \mathrm{kV} \\
+1 \times 132 \mathrm{kV}\end{array}$ \\
\hline 90.130 & Pradella & La Punt & 2017 & 2020 & $\mathrm{U}$ & $2 \times 380 \mathrm{kV}$ \\
\hline
\end{tabular}


Table 5 continued

\begin{tabular}{|c|c|c|c|c|c|c|}
\hline $\begin{array}{l}\text { ENTSOE } \\
\text { Project } \\
\text { Index }\end{array}$ & Substation 1 & Substation 2 & $\begin{array}{c}\text { ENSTOE } \\
\text { expected } \\
\text { year }\end{array}$ & $\begin{array}{l}\text { Base } \\
\text { case } \\
\text { year }\end{array}$ & $\begin{array}{l}\text { New } \\
\text { or } \\
\text { Upg. }\end{array}$ & Target type \\
\hline \multirow[t]{4}{*}{90.133} & Mettlen & Siebnen & 2020 & 2020 & U & $2 \times 380 \mathrm{kV}$ \\
\hline & Siebnen & Grynau & 2020 & 2020 & $\mathrm{U}$ & $2 \times 380 \mathrm{kV}$ \\
\hline & Grynau & Rüthi & 2020 & 2020 & $\mathrm{U}$ & $\begin{array}{c}1 \times 380 \mathrm{kV} \\
+1 \times 220 \mathrm{kV}\end{array}$ \\
\hline & Rüthi & Bonaduz & 2020 & 2025 & $\mathrm{U}$ & $1 \times 380 \mathrm{kV}$ \\
\hline 91.125 & Swanden & Limmern & 2015 & 2015 & $\mathrm{~N}$ & $2 \times 380 \mathrm{kV}$ \\
\hline 91.795 & Swanden & Limmern & 2015 & 2015 & $\mathrm{~N}$ & $2 \times 380 \mathrm{kV}$ \\
\hline 91.126 & Golbia & Robbia & 2019 & - & $\mathrm{N}$ & - \\
\hline 91.127 & Magadino & Verzasca & 2020 & - & $\mathrm{U}$ & - \\
\hline 31.124 & Mettlen & Airolo & 2020 & 2025 & U & $1 \times 380 \mathrm{kV}$ \\
\hline \multicolumn{7}{|c|}{ Crossborder } \\
\hline 90.136 & Border area (DE-AT) & Rüthi $(\mathrm{CH})$ & 2022 & 2025 & $\mathrm{~N}$ & $380 \mathrm{kV}$ \\
\hline 31.642 & Airolo $(\mathrm{CH})$ & Pallanzeno (IT) & 2022 & 2025 & $\mathrm{~N}$ & $220 \mathrm{kV}$ \\
\hline 174. 1014 & Verderio (I) & Sils $(\mathrm{CH})$ & 2018 & 2020 & $\mathrm{~N}$ & $\begin{array}{l}\text { HVDC } \\
400 \mathrm{kV}\end{array}$ \\
\hline 199. 1051 & Cornier (FR) & Chavalon $(\mathrm{CH})$ & 2025 & 2025 & $\mathrm{U}$ & $400 \mathrm{kV}$ \\
\hline \multicolumn{7}{|c|}{ Neighboring Countries } \\
\hline 21.55 & Grande Ile (FR) & Piossasco (IT) & 2019 & 2020 & $\mathrm{~N}$ & $\begin{array}{c}\text { HVDC } \\
2 \times 600 \mathrm{MW}\end{array}$ \\
\hline 988.989 & Muhlbach (FR) & Eichstetten (DE) & 2026 & 2030 & $\mathrm{U}$ & $400 \mathrm{kV}$ \\
\hline 26.63 & Lienz (AT) & Veneto region (IT) & 2023 & 2025 & $\mathrm{U}$ & $380 \mathrm{kV}$ \\
\hline 26. 614 & Nauders (AT) & Glorenza (IT) & 2018 & 2020 & $\mathrm{~N}$ & $220 \mathrm{kV}$ \\
\hline 26. 1049 & tbd (IT) & tbd (AT) & 2023 & - & & - \\
\hline 31.914 & Cassano (IT) & Chiari (IT) & 2022 & 2025 & $\mathrm{U}$ & $380 \mathrm{kV}$ \\
\hline 210. 1071 & Würmlach (AT) & Somplago (IT) & 2017 & 2020 & $\mathrm{~N}$ & $380 \mathrm{kV}$ \\
\hline 112 & Tirano (IT) & Verderio (IT) & 2030 & 2030 & $\mathrm{~N}$ & $400 \mathrm{kV}$ \\
\hline 47.218 & Obersielach (AT) & Lienz (AT) & 2023 & 2025 & $\mathrm{~N}$ & $380 \mathrm{kV}$ \\
\hline
\end{tabular}


Table 5 continued

\begin{tabular}{|c|c|c|c|c|c|c|}
\hline $\begin{array}{l}\text { ENTSOE } \\
\text { Project } \\
\text { Index }\end{array}$ & Substation 1 & Substation 2 & $\begin{array}{l}\text { ENSTOE } \\
\text { expected } \\
\text { year }\end{array}$ & $\begin{array}{l}\text { Base } \\
\text { case } \\
\text { year }\end{array}$ & $\begin{array}{l}\text { New } \\
\text { or } \\
\text { Upg. }\end{array}$ & Target type \\
\hline 47.212 & Isar (DE) & St. Peter (AT) & 2018 & 2020 & $\mathrm{~N}$ & $400 \mathrm{kV}$ \\
\hline 47.216 & St. Peter (AT) & Tauern (AT) & 2020 & 2020 & $\mathrm{U}$ & $380 \mathrm{kV}$ \\
\hline 47.219 & Westtirol (AT) & Zell-Ziller (AT) & 2021 & 2025 & $\mathrm{U}$ & $220 \mathrm{kV}$ \\
\hline 47.689 & Vöhringen (DE) & Westtirol (AT) & 2020 & 2020 & $\mathrm{U}$ & $380 \mathrm{kV}$ \\
\hline 189.997 & Pleinting (DE) & St. Peter (AT) & 2022 & 2025 & $\mathrm{U}$ & $380-\mathrm{kV}$ \\
\hline 1043 & Neuravensburg (DE) & Sigmarszell (DE) & 2020 & 2020 & $\mathrm{U}$ & $380 \mathrm{kV}$ \\
\hline 198.984 & Herbertingen (DE) & Tiengen (DE) & 2020 & 2020 & $\mathrm{U}$ & $380 \mathrm{kV}$ \\
\hline 198.986 & Wullenstetten (DE) & Niederwangen (DE) & 2020 & 2020 & U & $380 \mathrm{kV}$ \\
\hline
\end{tabular}

\section{References}

BAFU (2012), „Einzugsgebietsgliederung Schweiz EZGG-CH“, URL http:// www.bafu.admin.ch/ezgg-ch.

Capros, Pantelis (2013), "The PRIMES Model 2013-2014: Detailed Model Description", URL http://www.e3mlab.ntua.gr/e3mlab/PRIMES\%20 Manual/The\%20PRIMES\%20MODEL\%202013-2014.pdf.

Consentec (2012a), „Auswirkungen eines verstärkten Ausbaus der dezentralen Erzeugung auf die Schweizer Verteilnetze“, URL http://www.bfe.admin.ch/ $\mathrm{php} /$ modules/publikationen/stream.php?extlang=de\&name=de_519518234. pdf.

Consentec (2012b), „Einfluss verschiedener Stromangebotsvarianten auf das Übertragungsnetz der Schweiz", URL http://www.bfe.admin.ch/php/modules/publikationen/stream.php?extlang=de\&name=de_734620830.pdf.

Egerer, Jonas, Clemens Gerbaulet, Richard Ihlenburg, Friedrich Kunz, Benjamin Reinhard, Christian von Hirschhausen, AlexanDer Weber, and Jens Weibezahn (2014), "Electricity Sector Data for PolicyRelevant Modeling: Data Documentation and Applications to the German and European Electricity Markets", URL http://www.diw.de/documents/pub likationen/73/diw_01.c.440963.de/diw_datadoc_2014-072.pdf. 
Egerer, Jonas, Casimir Lorenz, and Clemens Gerbaulet (2013), "European Electricity Grid Infrastructure Expansion in a 2050 Context", EEM 2013, 10th International Conference on the European Energy Market 2013.

ENTSO-E (2013), "Yearly Statistics \& Adequacy Retrospect 2012", URL https:// www.entsoe.eu/publications/statistics/yearly-statistics-and-adequacy-retro spect/Pages/default.aspx.

ENTSO-E (2014), “Ten-Year Network Development Plan 2014: Full Report: Report to be Improved Based on the Stakeholders' Comments after the Public Consultation", URL https://www.entsoe.eu/major-projects/ten-year-networkdevelopment-plan/tyndp-2014/Pages/default.aspx.

European Commission (2011), "Energy Infrastructure: Priorities for 2020 and beyond - A Blueprint for an Integrated European Energy Network".

European Commission (2013), "Trends to 2050: EU Energy, Transport and GHG Emissions Reference Scenario 2013”, URL http://ec.europa.eu/transport/media/publications/doc/trends-to-2050-update-2013.pdf.

Fischer, Reinhard, and Friedrich Kiessling (1989), Freileitungen: Planung, Berechnung, Ausführung, 3rd edn., Berlin: Springer.

Fürsch, Michaela, Simeon Hagspiel, Cosima Jägemann, Stephan Nagl, Dietmar Lindenberger, and Eckehard Tröster (2013), "The Role of Grid Extensions in a Cost-Efficient Transformation of the European Electricity System until 2050", Applied Energy, pp. 642-652, URL http://dx.doi. org/10.1016/j.apenergy.2012.11.050.

Hergert, Rico (2013), Erneuerbare Energien aus der Landschaft Schweiz: Potentialberechnung unter Berücksichtigung verschiedener landschaftlicher Ausschlusskriterien und künftig nutzbarer Flächen, Ph.D. thesis, ETH Zürich, Zürich.

Hirth, Lion (2013), "The Market Value of Variable Renewables. The Effect of Solar Wind Power Variability on Their Relative Price", Energy Economics, 38, pp. 218-236, URL http://dx.doi.org/10.1016/j.eneco.2013.02.004.

Leuthold, Florian U., Hannes Weigt, and Christian von Hirschhausen (2012), "A Large Scale Spatial Optimization Model of the European Electricity Market", Networks and Spatial Economics: A Journal of Infrastructure Modeling and Computation, 12(1), pp. 75-107.

Mathys, Nicole A., Philippe Thalmann, and Marc Vielle (2012), "Modelling Contributions to the Swiss Energy and Environmental Challenge: Special Issue on Energy Modelling: Introductory Article", Swiss Journal of Economics and Statistics, 148(2), pp. 97-109.

Meтеотеsт (2012), „Berechnung der Energiepotenziale für Wind- und Sonnenenergie: Energiestrategie 2050: Commissioned by the Federal Office for the Environment (FOEN)“, URL http://www.bafu.admin.ch/ 
landschaft/00522/01659/index.html?lang=de\&download=NHzLpZeg7t,lnp 6I0NTU04212Z6ln1acy4Zn4Z2qZpnO2Yuq2Z6gpJCGfIR9gGym162epY bg2c_JjKbNoKSn6A--.

Prognos AG (2012), "Die Energieperspektiven für die Schweiz bis 2050: Energienachfrage und Elektrizitätsangebot in der Schweiz 2000-2050", URL http://www.bfe.admin.ch/php/modules/publikationen/stream.php?extlang= de\&name=de_564869151.pdf.

Schlecht, Ingmar, and Hannes Weigt (2014), "Swissmod: A Model of the Swiss Electricity Market”, WWZ Discussion Paper 2014/04, URL http://wwz. unibas.ch/uploads/tx_x4epublication/Swissmod_Schlecht_Weigt_2014.04. pdf.

Schweppe, Fred C., Michael C. Caramanis, Richard D. Tabors, and Roger E. Bohn (1988), Spot Pricing of Electricity, The Kluwer International Series in Engineering and Computer Science. Power Electronics and Power Systems, Boston: Kluwer Academic.

SFOE (2009), „Sachplan Übertragungsleitungen (SÜL)“, URL http://www. bfe.admin.ch/php/modules/publikationen/stream.php?extlang=de\&name =de_473856684.pdf.

SFOE (2011), „Kurzbericht Netze“, URL http://www.bfe.admin.ch/php/modules/ publikationen/stream.php?extlang=de\&name=de_840756874.pdf.

SFOE (2012a), „Energiestrategie 2050: Bericht des Teilprojekts Energienetze und Ausbaukosten", URL http://www.bfe.admin.ch/php/modules/publikationen/ stream.php?extlang=de\&name=de_659942037.pdf.

SFOE (2012b), „Erläuternder Bericht zur Energiestrategie 2050“, URL http://www. bfe.admin.ch/themen/00526/00527/index.html?lang=de\&dossier_id=05773.

SFOE (2012c), „Statistik der Wasserkraftanlagen (WASTA)“, URL http://www. bfe.admin.ch/geoinformation/05061/05249/index.html?lang=de.

SFOE (2013), „Strategie Stromnetze: Detailkonzept im Rahmen der Energiestrategie 2050", URL http://www.bfe.admin.ch/php/modules/publikationen/ stream.php?extlang $=$ de\&name $=$ de_799448366.pdf.

Singh, Antriksh, David Willi, Ndaona Chokani, and Reza S. Abhari (2014), "Optimal Power Flow Analysis of Switzerland's Transmission System for Long-Term Capacity Planning”, Renewable and Sustainable Energy Reviews, pp. 596-607, URL http://dx.doi.org/10.1016/j.rser.2014.03.044.

SwISSGRID (2012), „Energiewende: Übertragungsnetz mit Schlüsselrolle“, URL http://www.swissgrid.ch/dam/swissgrid/company/publications/de/ Energiewende_de.pdf.

SwISSGRID (2014a), „Das Netz der Zukunft“, URL http://www.swissgrid.ch/ swissgrid/de/home/grid/development.html. 
SwISSGRID (2014b), „Netzausbau“, URL http://www.swissgrid.ch/swissgrid/de/ home/grid/grid_expansion.html.

Wu, Felix, Pravin Varaiya, Pablo Spiller, and Shmuel Oren (1996), "Folk Theorems on Transmission Access: Proofs and Counterexamples", Journal of Regulatory Economics, 10(1), pp.5-23, URL http://dx.doi.org/10.1007/ BF00133356.

\section{SUMMARY}

The aim of this paper is to evaluate the role of the Swiss electricity transmission system and the planned network extensions in the context of Central European electricity market developments and thereby the Swiss and European energy transitions. In addition, we conduct a sensitivity analysis of delayed grid investments for Swiss and European network projects, respectively. By utilizing a numerical model representation of the Swiss electricity market Swissmod we derive a quantification of the different effects and developments up to 2050. In summary, the Central European market will largely be influenced by the significant increase in intermittent renewable generation. Whereas current power flow patterns are mostly from the Northern markets towards Italy using Switzerland as a transit hub, the large share of solar capacities in 2050 will lead to a high variability on shorter timeframes. While Switzerland will remain a transit hub, the import and export flows will vary with season and daytime. The potential costs and system impacts due to delayed network investments are rather modest in comparison to the overall generation costs but can nevertheless sum to 700 million per year highlighting the importance of network extension to improve cross-regional energy exchange. 